University of Nebraska - Lincoln

DigitalCommons@University of Nebraska - Lincoln

Faculty Publications, Department of Psychology

Psychology, Department of

March 1996

\title{
Conditioned Stimulus Determinants of Conditioned Response Form in Pavlovian Fear Conditioning
}

Stephen D. Kim

University of Massachusetts, Amherst

Steven Rivers

University of Massachusetts, Amherst

Rick A. Bevins

University of Nebraska-Lincoln, rbevins1@unl.edu

John J. B. Ayres

University of Massachusetts, Amherst

Follow this and additional works at: https://digitalcommons.unl.edu/psychfacpub

Part of the Psychiatry and Psychology Commons

Kim, Stephen D.; Rivers, Steven; Bevins, Rick A.; and B. Ayres, John J., "Conditioned Stimulus Determinants of Conditioned Response Form in Pavlovian Fear Conditioning" (1996). Faculty Publications, Department of Psychology. 208.

https://digitalcommons.unl.edu/psychfacpub/208

This Article is brought to you for free and open access by the Psychology, Department of at DigitalCommons@University of Nebraska - Lincoln. It has been accepted for inclusion in Faculty Publications, Department of Psychology by an authorized administrator of DigitalCommons@University of Nebraska - Lincoln. 
Published in Journal of Experimental Psychology: Animal Behavior Processes 22:1 (1996), pp. 87-104. Copyright (C1996 by the American Psychological Association, Inc. Used by permission. "This article may not exactly replicate the final version published in the APA journal. It is not the copy of record."

\title{
Conditioned Stimulus Determinants of Conditioned Response Form in Pavlovian Fear Conditioning
}

\author{
Stephen D. Kim, Steven Rivers, Rick A. Bevins, \\ and John J. B. Ayres \\ University of Massachusetts, Amherst
}

\begin{abstract}
Four experiments using barpress conditioned suppression in rats found that tone evoked more freezing (immobility) than did light. Still, tone and light appeared to have similar conditioned value as assessed by suppression in Experiments 1, 2, and 3, and by blocking, second-order conditioning, and overconditioning assays in Experiments 1, 2, and 3, respectively. Experiment 4 arranged for tone to evoke less suppression than light but more freezing. Results suggest that in fear conditioning, the nature of the conditioned stimulus affects the form of conditioned responding (strong vs. weak freezing). This conclusion extends one drawn by P. C. Holland (1977) on the basis of his work in appetitive conditioning.
\end{abstract}

The most thorough demonstration that the nature of the conditioned stimulus (CS) affects the form of the conditioned response (CR) is that of Holland (1977). Using rats in an appetitive situation, Holland found that tones paired with food evoked head-jerk and startle CRs, whereas lights paired with food evoked the CRs of rearing and orienting toward the food tray. Holland then asked whether these different behaviors might reflect different conditioned values of tone and light. In separate experiments, he assessed those values in two ways: (a) by measuring the ability of tone and light to serve as blockers in Kamin's (1968) two-stage blocking procedure and (b) by assessing their ability to serve as second-order reinforcers. In the blocking experiment, Holland paired a tone + light compound CS with food. He found that if the light had previously been conditioned, it would block the conditioning of head-jerk and startle to the formerly neutral tone. If the tone had previously been conditioned, it would block the conditioning of tray orientation to the formerly neutral light. It is notable that in each case, the blocker had the ability to block the conditioning of a behavior that it rarely evoked itself. In a

Stephen D. Kim, Steven Rivers, Rick A. Bevins, and John J. B. Ayres, Department of Psychology, University of Massachusetts, Amherst.

Stephen Kim conducted Experiments 1 and 2 for a senior honors thesis and was assisted by Steven Rivers and supervised by Rick Bevins. Rick Bevins conducted Experiment 3 with the assistance of Donna Blair. John Ayres conducted Experiment 4 and was assisted by Janice McPhee, Tony Rauhut, and Michelle Wynn in scoring freezing. The work was conceived by John Ayres, who also prepared the article. The project was supported in part by National Science Foundation Grant 87-22173, by National Institute of Mental Health Grant MH50491-01, and by a faculty research grant. We thank Mark E. Bouton for his comments on the article.

Correspondence concerning this article should be addressed to John J. B. Ayres, Department of Psychology, University of Massachusetts, Amherst, Massachusetts 01003. similar manner, in the second-order conditioning experiment, Holland paired a neutral low-pitched tone with a conditioned light in one group and with a conditioned high-pitched tone in a second group. He found that the second-order CS (the lowpitched tone) came to evoke the same level of head-jerk and startle CRs in both groups. That result was remarkable in that only one of the first-order CSs (the high-pitched tone) itself evoked these behaviors. Thus, tone and light supported similar second-order conditioning despite the differences in the CRs that they themselves evoked. On the basis of both his blocking and his second-order conditioning data, Holland concluded that his tones and lights had similar associative values but evoked CRs of different forms.

Recent evidence suggests that Holland's conclusions may also apply to Pavlovian fear conditioning. Feared CSs in different modalities may evoke defensive CRs of differing forms. Specifically, when paired with shock unconditioned stimuli (USs), auditory CSs, such as tones or white noise, often evoke more freezing (defensive immobility) than do visual CSs, such as increases or decreases in light (Albert, 1990; Ayres, Axelrod, Mercker, Muchnik, \& Vigorito, 1985; Bevins \& Ayres, 1991, 1992; Helmstetter \& Fanselow, 1989; Sigmundi \& Bolles, 1983; Sigmundi, Bouton, \& Bolles, 1980; van Willigen, Emmett, Cote, \& Ayres, 1987). As in Holland's work, it appears that the auditory and visual CSs have similar conditioned values. The evidence is that they have similar ability to (a) overshadow contextual cues (Sigmundi \& Bolles, 1983), (b) serve as reinforcers for the second-order conditioning of contextual cues (Helmstetter \& Fanselow, 1989), and (c) evoke barpress suppression (Ayres et al., 1985; Bevins \& Ayres, 1991, 1992). The similar barpress suppression evoked by auditory and visual CSs, moreover, does not appear to be due to a ceiling effect. Bevins and Ayres (1991) showed that when visual and auditory 
Kim, Rivers, Bevins, \& Ayres in JEP:ABP 22 (1996)

CSs were compounded, they evoked more suppression together than did either CS alone. Thus, there was "room" for more suppression to the auditory CS than to the visual CS if indeed the auditory CS had the greater value.

When Sigmundi et al. (1980) first found that light evoked less freezing than white noise, they assumed that light was feared just as much as noise but supported a different form of defensive behavior. When Ayres et al. (1985) found similar barpress suppression to light and tone despite the greater freezing to tone, they too accepted that assumption. They assumed that if light evoked less freezing, then it must evoke more of some other defensive response that was equally incompatible with barpressing. Subsequently, several workers (Albert, 1990; Fanselow \& Lester, 1988) carefully examined the behavior evoked by conditioned aversive lights, seeking to discover the nature of this "other" defensive response. They were unable to identify any such response.

Because no unique defensive behavior to light has been found despite intensive search, it seems important to reopen the question of whether lights and tones with identical conditioning histories really do have similar conditioned values. If they do not, then the greater freezing evoked by tone may be due only to tone's greater value. Previous evidence for similarity in their values (Ayres et al., 1985; Bevins \& Ayres, 1991, 1992; Helmstetter \& Fanselow, 1989; Sigmundi \& Bolles, 1983) may have relied on insensitive measures.

In our studies, we compared the conditioned values of tone and light by using three different measures: blocking, secondorder conditioning, and overconditioning. We chose a situation in which tone was known to evoke more freezing than light but similar barpress suppression (Bevins \& Ayres, 1991). Then, following Holland's lead, we assessed (in Experiment 1) the ability of the tone and light to block conditioning to some third punctate CS and (in Experiment 2) to reinforce second-order conditioning to a third punctate CS. If tone and light have similar conditioned values despite the different levels of freezing they evoke, then they should have similar abilities to block conditioning to the third CS and similar abilities to reinforce second-order conditioning to the third CS. In Experiment 3, we measured responding to tone and light after they had first been conditioned separately to asymptote then further conditioned in compound, a procedure termed overconditioning (Rescorla, 1970). Overconditioning was expected to weaken responding to both elements (Rescorla \& Wagner, 1972). Of special interest here is the following point: If a light evokes weak freezing because it is poorly conditioned, then there would be little theoretical reason for overconditioning to weaken the CR to the tone (Rescorla \& Wagner, 1972). So if the CR to tone is indeed weakened by overconditioning, then the light must have been well conditioned. Finally, in Experiment 4, we sought to create a situation in which tone would evoke weaker barpress suppression than light and still evoke more freezing. Evidence for such a "double dissociation" would strongly imply that tone's ability to evoke more freezing was not due to its stronger conditioned value.

\section{Experiment I: Blocking}

\author{
Method
}

\section{Subjects}

Sixteen male and 16 female experimentally naive Holtzman-derived albino rats were bred in a continuously lighted colony at the University of Massachusetts, Amherst. The rats were housed singly in stainless steel cages with free access to water. Free-feeding weights ranged from 226 to $338 \mathrm{~g}$ in the female rats and from 413 to $541 \mathrm{~g}$ in the male rats. Limited feeding, which began 7 days before the experiment, lowered these weights $20 \%$ and kept them at that level. For reasons unrelated to the study, the colony lighting was changed to a 16:8-hr light:dark cycle, beginning about 1 month before experimentation. Experimental sessions occurred in the light part of that cycle.

\section{Apparatus}

Eight operant boxes (Gerbrands Corporation, Arlington, MA, now out of business) were housed in ventilated .61-m cubes of 12.7mm plywood lined with acoustical tile. Each cube had a doublepaned Plexiglas door that allowed full view of the rats yet preserved sound attenuation. Outside and above the cubes and out of the rats' line of sight were a relay and Some $28-\mathrm{V}$ indicator lamps. These devices paced the scoring of freezing (see Procedure) by cycling on for $1.4 \mathrm{~s}$ then off for .1 s throughout each session.

The inside dimensions of each operant box were $23.2 \times 20.3 \times$ $19.5 \mathrm{~cm}$. Each floor was made of 18 stainless steel rods $(2 \mathrm{~mm}$ in diameter) spaced $1.3 \mathrm{~cm}$ apart center to center. The end walls were aluminum. The side walls and lid were clear Plexiglas. Centered in one end wall was an operant bar $(5 \times 1.5 \mathrm{~cm})$ mounted $8 \mathrm{~cm}$ above the floor. In the lower left corner of this wall was a recessed dipper tray $(5 \times 5 \times 5.5 \mathrm{~cm})$.

On each box lid were two speakers (10-cm diameter). One provided a $1000-\mathrm{Hz}$ tone $\mathrm{CS}(\mathrm{T})$ of $86 \mathrm{~dB}$. The other provided continuous background white noise of $80 \mathrm{~dB}$. The cessation of this white noise constituted another CS ( $\mathrm{N}$ ). That cessation left a background noise of about $67 \mathrm{~dB}$, provided mainly by an exhaust fan. A light CS (L) was provided by a white frosted bulb $(7.5-\mathrm{W}, 110-\mathrm{V})$ mounted on the rear wall of the housing cube. Background lighting was provided by a similar but red frosted bulb mounted on the same wall. A 24-V relay (KHP17D11, Potter \& Brumfield, Marion, KY) was bolted through its plastic casing to the outer surface of the Plexiglas wall to the rat's right as it faced the bar. When operated 333 times per minute, it provided an $85-\mathrm{dB}$ click CS (C). Scrambled grid shocks $(0.8 \mathrm{~mA}$ for $1 \mathrm{~s})$, provided by Grason-Stadler shock sources (Models E1064 and 700, Grason-Stadler Company, West Concord, MA) served as USs. Barpressing, the response to be suppressed by CSs, was maintained with 4-s deliveries of a 0.1 $\mathrm{ml}$ dipper cup of $32 \%$ liquid sucrose. The intensities of the auditory CSs were measured by using a sound level meter (Model 1565-B, General Radio, Concord, MA) set on the Cs scale with the microphone placed about $7 \mathrm{~cm}$ from the food tray.

\section{Procedure}

Each rat received one session daily, 7 days per week. There were four phases: (a) preliminary training to establish a barpress baseline and to pretest T, L, C, and $\mathrm{N}^{-} \mathrm{CSs}$; (b) differential fear conditioning to condition fear to either $\mathrm{T}$ or $\mathrm{L}$ while leaving the other relatively neutral; (c) Compound conditioning in which $\mathrm{T}$ or $\mathrm{L}$ was reinforced in compound with an added stimulus, either $\mathrm{C}_{\text {or }} \mathrm{N}^{-}$; and 
(d) extinction testing designed to assess conditioning to that added stimulus. It should be noted that the four CSs were selected for use after extensive pilot work in which we repeatedly found no evidence for generalization among them.

Preliminary training. Preliminary training consisted of 1 day of magazine training, 3 days of barpress shaping plus food for each response, and 5 days of training on a variable interval (VI) 1-min schedule of reinforcement with a variable time 1-min limited hold. The rats were randomly assigned to four squads of eight, each with four males and four females. Beginning with VI training, all sessions were 1-hr long.

On the last 2 days of VI training, all four CSs were pretested so as to reduce their unconditioned effects. In the first pretest, the order of trials was T, C, L, and $\overline{\mathrm{N}}$ In the second pretest, the order was reversed. CSs were 2-min long throughout the experiment and, in this phase, began at the start of min. 11, 25, 39, and 52 .

Differential conditioning. For 8 days, half the rats received $\mathrm{T}$ paired with shock and received $\mathrm{L}$ explicitly unpaired $(\mathrm{T}+\mathrm{L}-)$. The remaining rats received the reverse $(\mathrm{T}-\mathrm{L}+)$. On each day, CSs began at the start of min 18 and 50. The order of CSs across the 8 days of differential conditioning was T L, L T, L T, T L, L T, T L, L T, and $\mathrm{T}$ L. In this phase, and throughout this research, the shock US always coterminated with its paired CS.

Compound conditioning. Over the next 4 days, half the rats that had received $\mathrm{T}+\mathrm{L}-$ now received $\mathrm{T}$ reinforced in compound with an added stimulus, $\overline{\mathrm{N}}(\overline{\mathrm{N}}+)$, and received L reinforced in compound with the added stimulus, $\mathrm{C}(\mathrm{LC}+)$. The other half received $\mathrm{TC}+$ and $\overline{\mathrm{N}}+$. Rats that had received $\mathrm{T}-\mathrm{L}+$ were treated similarly: Half received $\mathrm{L}$ $\overline{\mathrm{N}}+$ and $\mathrm{TC}+$, and half received $\mathrm{LC}+$ and $\overline{\mathrm{N}}+$. In short, for all rats, one added stimulus $(\mathrm{C}$ or $\overline{\mathrm{N}})$ was reinforced in compound with a conditioned excitor ( $\mathrm{T}$ or $\mathrm{L})$, and the other added stimulus $(\mathrm{C}$ or $\overline{\mathrm{N}})$ was reinforced in compound with a nonexcitor ( $\mathrm{T}$ or $\mathrm{L}$ ). Kamin blocking was expected to the added CS reinforced in compound with the excitor but not to the added CS reinforced in compound with the nonexcitor. The design thus provided a within-subject control for blocking.

Testing. Testing for conditioning to the added stimulus, $\overline{\mathrm{N}}$ or $\mathrm{C}$, consisted of 4 days of Pavlovian extinction trials, during which barpress suppression and freezing evoked by $\overline{\mathrm{N}}$ and $\mathrm{C}$ were measured. On Days 1 and 3, C began at the start of min 18, and $\bar{N}$ began at the start of min 50. On Days 2 and 4, the order was reversed.

Direct observations. Beginning on Day 1 of differential conditioning, freezing was scored using a time sampling procedure (Sigmundi et al., 1980). For $5 \mathrm{~s}$ before each 2-min pre-CS period, indicator lamps above the housing cubes lit up to alert the observers. At the end of this cue, the observers scored the behavior of the rat in Box 1 and then, paced by relay clicks, scored the behavior of the rats in Boxes 2, 3, and 4 in turn before returning to Box 1 . There were 10 ratings per minute per rat. Only four rats in each squad of eight were rated on a given day - rats in Boxes 1-4 on odd days, rats in Boxes 5-8 on even days. Each sample was scored as freezing or not freezing. Freezing was defined as the absence of any movement except that of the rat's sides required to breathe. Not freezing was defined as anything else. On each trial, a rat was given a probability-of-freezing, $p$ (freezing), score. That score was simply the number of samples scored as freezing during a CS divided by the number of samples in that period. Two trained observers (Kim and Rivers) rated the same rats simultaneously on $62 \%$ of the trials so as to provide a reliability check. The Pearson product-moment correlation coefficient between their $p$ (freezing) scores on these trials was .86. The remaining $38 \%$ of the trials were divided about equally between the two observers. Because each observer rated about the same number of trials, there was no basis for choosing one's scores over the other's when they both observed on the same trials. Therefore, when ratings from both observers were available, the means of their $p$ (freezing) scores were used as the best estimate of freezing.

Barpress suppression measure. Barpress suppression was expressed as a ratio formed by dividing the number of responses during the 2-min CS by the sum of that number plus the number in the 2min pre-CS period (Annau \& Kamin, 1961). With this ratio, a score of .5 denotes no effect of the CS, and a score of 0 denotes total suppression during the $\mathrm{CS}$.

Rejection region. Unless noted otherwise, all statistical tests of both the freezing and suppression data used a two-tailed rejection region of .05.

\section{Results}

\section{Differential Conditioning}

As shown in Figure 1, barpress suppression and freezing were rarely evoked by $\mathrm{T}$ and $\mathrm{L}$ when these cues were explicitly unpaired with shock; however, when reinforced, T and L came to evoke similar levels of suppression at the same time that $\mathrm{T}$ evoked much more freezing than did $\mathrm{L}$.

Modality $\times$ Measure analyses of variance (ANOVAs) were conducted separately on the freezing and suppression to explicitly unpaired CSs (T- and $\mathrm{L}-$ ) and to reinforced CSs (T+ and $\mathrm{L}+$ ). The ANOVA on barpress suppression to $\mathrm{T}+$ and $\mathrm{L}+$ revealed significant effects of modality, $F(1,30)=5.85$, and the Modality $\times$ Measure interaction, $F(3,90)=5.21$, reflecting the faster conditioning to $\mathrm{T}$; however, by the end of training, suppression was clearly similar to those two CSs (see Figure 1). The ANOVA on freezing to $\mathrm{T}+$ and $\mathrm{L}+$ also revealed significant effects of modality, $F(1,30)=15.41$, and Modality $\times$ Measure, $F(3,90)=6.36$, indicating that freezing to $\mathrm{T}$ increased more with training than did freezing to L. By the end of training, T clearly evoked more freezing than did L, (see Figure 1).

\section{Compound Conditioning}

Figure 2 shows that at the start of compound conditioning, the compounds that contained an already reinforced element (see $\mathrm{T}+$ and $\mathrm{L}+$ curves) produced strong suppression and freezing, whereas those containing a formerly nonreinforced element (see $\mathrm{T}-$ and $\mathrm{L}-$ curves) did not. Because all compounds were reinforced in this phase, suppression and freezing increased with training to compounds containing formerly nonreinforced elements ( $\mathrm{T}-$ or $\mathrm{L}-$ ). By the end of training, all compounds evoked strong suppression and freezing.

For the suppression data in compound training, a Modality $\times$ Sign $(+$ or -$) \times$ Measure ANOVA revealed significant effects of sign, measure, and their interaction, $F_{\mathrm{S}}(1,30)>52.18$. For the freezing data, a similar ANOVA revealed a significant effect of measure and the Sign $\times$ Measure interaction, $F \mathrm{~s}(1$, $30)>5.33$. These analyses confirm the impression in Figure 2 that suppression and freezing increased across measures more for compounds containing $\mathrm{T}$ - or $\mathrm{L}$ - than for compounds containing $\mathrm{T}+$ or $\mathrm{L}+$.

It is notable that at the start of compound conditioning, the compound containing $\mathrm{T}+$ tended to evoke less suppression 

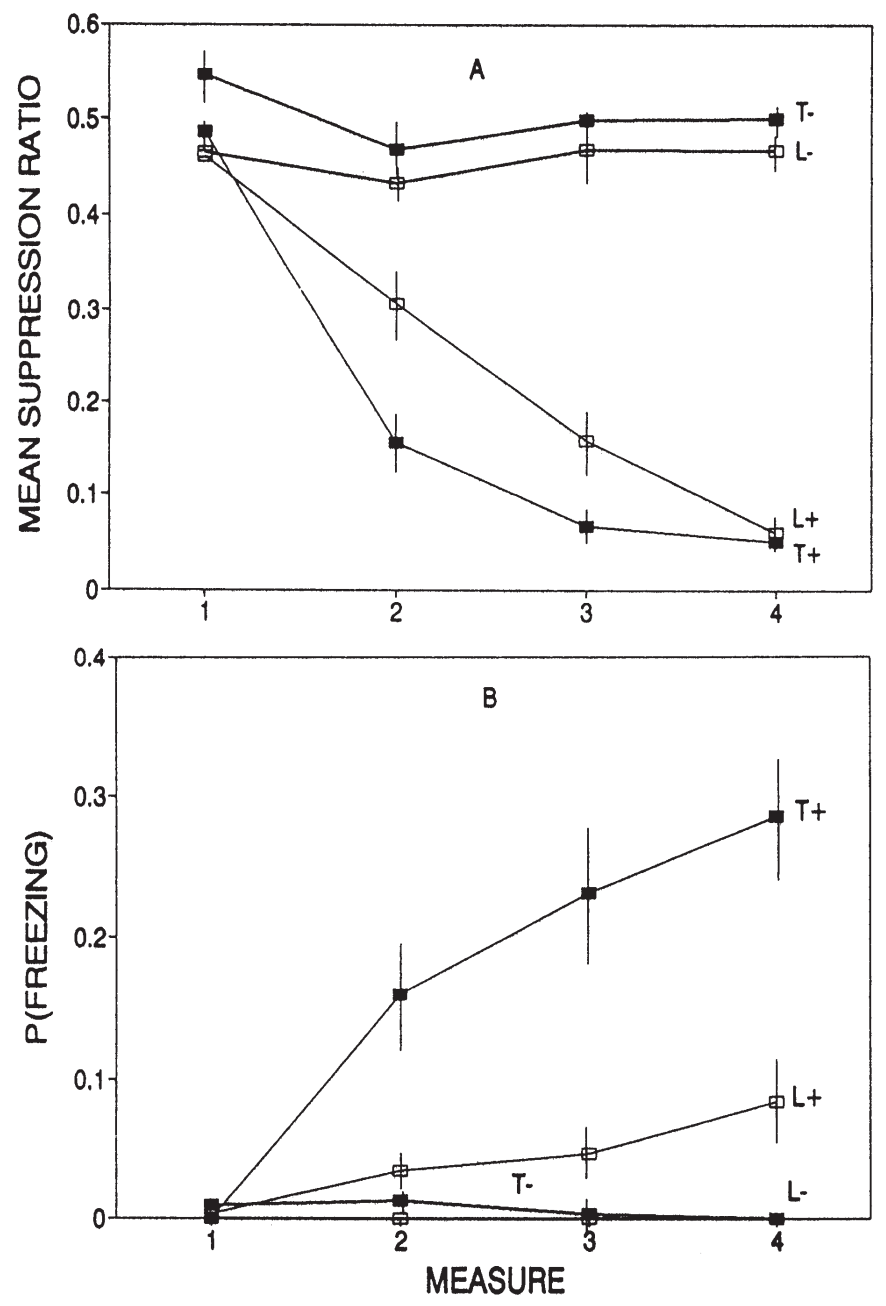

Figure 1. Acquisition of barpress suppression (Panel A) and freezing (Panel B) during differential conditioning in Experiment 1. Measure 1 combines the data from Rats $1-4$ of each squad on Day 1 with the data from Rats 5-8 on Day 2. Measure 2 combines the data from Rats $1-4$ on Day 3 with the data from Rats $5-8$ on Day 4, and so on. Vertical lines through data points show plus and/or minus one standard error of the mean.

and less freezing than did the compound containing $\mathrm{L}^{+}$, even though $\mathrm{T}+$ alone evoked more freezing in the previous phase. This result suggests that $\mathrm{T}$ was more subject to external inhibition by the added element $\left(\mathrm{C}\right.$ or $\left.\mathrm{N}^{-}\right)$than was $\mathrm{L}$. If we assume that a more highly valued CS should be more resistant to external inhibition, then we would assume that $\mathrm{L}$ had at least as much value as T, despite evoking less freezing in the previous phase. The results of the blocking test (later) will support that assumption.

\section{Extinction Test for Blocking}

In the extinction test for blocking to the $\mathrm{C}$ and $\overline{\mathrm{N}}$ elements, the main finding was that suppression and freezing were weaker if in the preceding phase the $\mathrm{C}$ and $\overline{\mathrm{N}}$ elements had been reinforced in compound with $\mathrm{T}+$ or $\mathrm{L}+$ as against $\mathrm{T}-$ or $\mathrm{L}-$. In
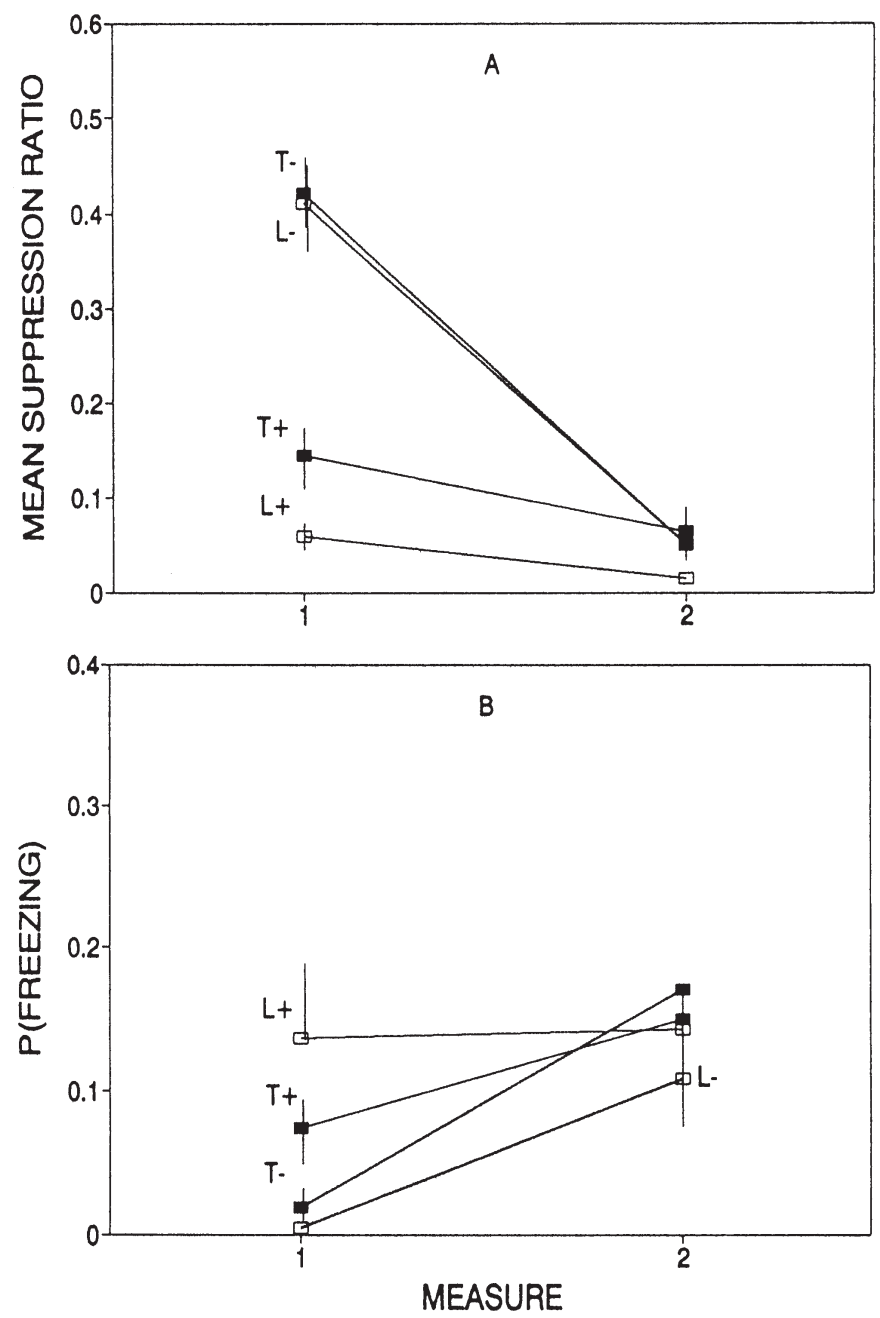

Figure 2. Barpress suppression (Panel A) and freezing (Panel B) to $\mathrm{CS}$ compounds containing previously reinforced $(\mathrm{T}+$ and $\mathrm{L}+$ ) elements or previously nonreinforced ( $\mathrm{T}-$ and $\mathrm{L}-$ ) elements. Measure 1 combines the data from Rats $1-4$ of each squad on Day 1 with the data from Rats 5-8 on Day 2. Measure 2 combines the data from Rats $1-4$ on Day 3 with the data from Rats $5-8$ on Day 4, and so on. Vertical lines through data points show plus and/or minus one standard error of the mean.

short, blocking was observed. More important, $\mathrm{L}+$ appeared to block at least as well as did $\mathrm{T}+$. These results are shown in Figure 3 . Here, the $\mathrm{T}+$ and $\mathrm{L}+$ curves show the response to the added element whose mate ( $\mathrm{T}$ or $\mathrm{L}$ ) had been reinforced before compound conditioning. The $\mathrm{T}-$ and $\mathrm{L}-$ curves show the response to the added element whose mate ( $\mathrm{T}$ or $\mathrm{L}$ ) was nonexcitatory before compound conditioning. For half of the rats in each curve, the element tested was C. For the other half, the element tested was $\overline{\mathrm{N}}$. Plots of the $\overline{\mathrm{N}}$ and $\mathrm{C}$ data separately (not shown) revealed similar responding to the two CSs. The data for the two are therefore pooled to simplify the graphs. Figure $3 \mathrm{~A}$ shows that suppression was weaker to the added element that had been reinforced in compound with a known excitor $(\mathrm{T}+$ or $\mathrm{L}+)$ than to the added element that had been reinforced 

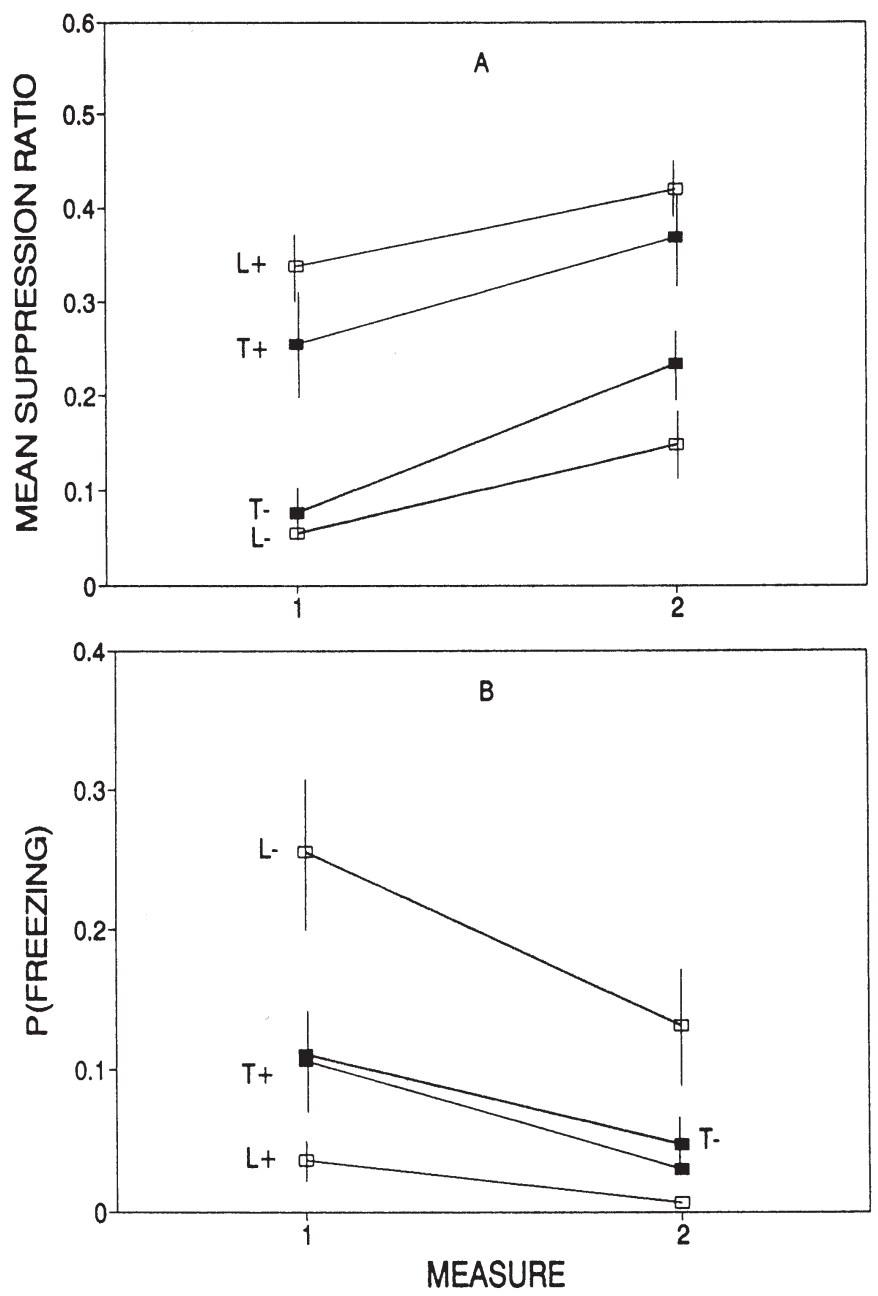

Figure 3. Extinction test of barpress suppression (Panel A) and freezing (Panel B) to target elements $\left(\mathrm{C}\right.$ and $\mathrm{N}^{-}$) that had been reinforced in compound with previously reinforced elements $(\mathrm{T}+$ and $\mathrm{L}+)$ or with previously nonreinforced elements ( $\mathrm{T}-$ and $\mathrm{L}-$ ). Measure 1 combines the data from Rats 1-4 of each squad on Day 1 with the data from Rats 5-8 on Day 2. Measure 2 combines the data from Rats 1-4 on Day 3 with the data from Rats 5-8 on Day 4, and so on. Vertical lines through data points show plus and/or minus one standard error of the mean.

in compound with a nonexcitor ( $\mathrm{T}-$ or $\mathrm{L}-$ ). That is, the conditioned excitors $(\mathrm{T}+$ and $\mathrm{L}+$ ) apparently blocked conditioning to $\mathrm{C}$ and $\overline{\mathrm{N}}$. Figure $3 \mathrm{~B}$ shows a similar effect for freezing. Freezing tended to be weaker to the element that had been reinforced in compound with a known excitor $(\mathrm{T}+$ or $\mathrm{L}+)$ than to the element that had been reinforced in compound with a nonexcitor ( $\mathrm{T}-$ or $\mathrm{L}-$ ). Both figures also show the effects of extinction during the test. Suppression weakened across measures (Figure 3A), as did freezing (Figure 3B).

For the suppression data in the extinction test for blocking, a Modality-of-CS $+\times$ Sign $\times$ Measures ANOVA revealed only the effects of sign and measures to be significant, $F_{\mathrm{s}}(1,30)$ $>$ 33.94. The sign effect reflects Kamin blocking. The measures effect reflects extinction of suppression across nonre- inforced test trials. A Modality $\times$ Measures ANOVA on just the $\mathrm{T}+\mathrm{L}+$ data revealed only a significant effect of measures, as did a similar ANOVA on just the T- L- data, $F \mathrm{~s}(1,30)>$ 15.34. These analyses thus suggest that the ability of $\mathrm{T}$ and $\mathrm{L}$ to block conditioning to a third $\mathrm{CS}(\mathrm{C}$ or $\overline{\mathrm{N}})$ was similar. A Modality-of-CS $+\times$ Sign $\times$ Measures ANOVA on the freezing data also revealed only the three main effects and no interactions to be significant, $F_{\mathrm{s}}(1,30)>6.15$. The sign and measure effects again reflect blocking and extinction, respectively. The modality-of-CS+ effect reflects the occurrence of slightly more freezing to the added CSs if their mate during compound conditioning had been $\mathrm{L}$ (mean $p[$ freezing] $=.11$ ) rather than $\mathrm{T}(M=.07)$. This difference suggests better overshadowing by $\mathrm{T}$, regardless of its conditioning history. A Modality $\times$ Measures ANOVA on just the $\mathrm{T}+\mathrm{L}+$ data revealed only a significant effect of measures, as did a similar ANOVA on just the $\mathrm{T}-\mathrm{L}-$ data, $F \mathrm{~s}(1,30)>7.06$. Like the analyses of barpress suppression, the analyses of freezing suggest that $\mathrm{T}$ and $\mathrm{L}$ had similar abilities to block.

\section{Pre-CS Responding}

Mean pre-CS barpress rates were 17, 19, and 20 responses per minute during differential conditioning, compound conditioning, and extinction testing, respectively. A Modality-of$\mathrm{CS}+\times$ Sign $\times$ Measure ANOVA was performed on the pre-CS response rates from the crucial test phase. It revealed no significant effects. Thus, barpress suppression effects described in that phase were not tainted by differences in pre-CS responding. Nor were there any problems in that phase due to differences in pre-CS freezing; there was no pre-CS freezing.

\section{Discussion}

Differential conditioning produced the data pattern (Ayres et al., 1985; Bevins \& Ayres, 1991, 1992) that we set out to interpret. Thus, by the end of that training, there was more freezing to $\mathrm{T}$ than to $\mathrm{L}$ but similar barpress suppression to both cues. This data pattern is subject to two mutually exclusive interpretations, as follows: (a) Freezing underrates the conditioned value of $\mathrm{L}$, and barpress suppression is the better measure of that value; and (b) barpress suppression underrates the conditioned value of $\mathrm{T}$, and freezing is the better measure of that value. If Interpretation (a) is correct, the results would imply that $\mathrm{T}$ and $\mathrm{L}$ evoke CRs of different forms (strong vs. weak freezing) despite having similar conditioned values. If Interpretation (b) is correct, the results suggest the less interesting conclusion that $\mathrm{T}$ evokes more freezing than $\mathrm{L}$ only because $\mathrm{T}$ has the greater conditioned value.

The extinction test for blocking (see Figure 3) was expressly designed to separate the two opposing interpretations. If at the end of differential conditioning, $\mathrm{T}$ is better conditioned than $\mathrm{L}$, as suggested by the freezing measure, then $\mathrm{T}$ should more effectively block conditioning to an added CS, such as $\overline{\mathrm{N}}$ or $\mathrm{C}$. However, if freezing underrates conditioning to $\mathrm{L}$ and if $\mathrm{T}$ and $\mathrm{L}$ are equally conditioned, as suggested by the barpress 
suppression measure, then they should have similar abilities to block conditioning to $\overline{\mathrm{N}}$ or $\mathrm{C}$.

The results of the extinction test for blocking suggest that $\mathrm{L}$ was at least as good a blocker as was $\mathrm{T}$. The blocking data are thus more consistent with the estimates of conditioning provided by the barpress suppression measure at the end of differential conditioning than with the estimates provided by the freezing measure. Therefore, the blocking results suggest that even though $\mathrm{T}$ and $\mathrm{L}$ had similar conditioned values, they evoked CRs of different form: strong freezing to $\mathrm{T}$ and weak freezing to $\mathrm{L}$.

\section{Experiment 2: Second-Order Conditioning}

At the end of differential conditioning in Experiment 1, the freezing measure suggested that $\mathrm{T}$ was more highly conditioned than $\mathrm{L}$. If that were true, then $\mathrm{T}$ should be the better reinforcer of second-order conditioning to some third stimulus. In contrast, the barpress suppression measure at the end of differential conditioning suggested that $\mathrm{T}$ and $\mathrm{L}$ had equal conditioned value. If that were true, then $\mathrm{T}$ and $\mathrm{L}$ should have similar abilities to reinforce second-order conditioning to some third stimulus.

Helmstetter and Fanselow (1989) showed that conditioned lights and tones had similar ability to reinforce second-order fear conditioning to contextual cues (ever-present apparatus cues), as measured by context-evoked freezing. Our study resembled that of Helmstetter and Fanselow but sought to second-order condition punctate CSs instead of contextual cues and measured both barpress suppression and freezing to all CSs. Moreover, by giving conditioning trials while the rat was barpressing and not just occupying an empty box, we expected clearer differences in the levels of freezing evoked by $\mathrm{T}$ and $\mathrm{L}$ than those obtained by Helmstetter and Fanselow (Bevins \& Ayres, 1992).

\section{Method}

\section{Subjects}

The subjects were 16 male and 16 female experimentally naive albino rats bred in our colony from Holtzman stock. Free-feeding weights ranged from 225 to $251 \mathrm{~g}$ in the female rats and from 353 to $373 \mathrm{~g}$ in the male rats. These weights were lowered $20 \%$ before the experiment and were kept at that level. The colony was lighted on a 16:8 hr light:dark cycle. As in Experiment 1, the rats were trained during the light part of that cycle.

\section{Apparatus}

The apparatus was unchanged.

\section{Procedure}

The procedure had the following six phases: (a) preliminary training designed to condition barpressing and to pretest T, L, C, and $\mathrm{N}^{-}$CSs; (b) differential conditioning designed to condition $\mathrm{T}$ or L while leaving the other neutral; (c) more pretesting designed to ensure the continued neutrality of $\mathrm{C}_{\text {and }} \mathrm{N}^{-}$; (d) second-order conditioning in which one untrained stimulus $\left(\mathrm{C} \mathrm{or} \mathrm{N}^{-}\right)$was followed immediately by a first-order fear excitor ( $\mathrm{T}$ or $\mathrm{L}$ ) and the other untrained stimulus $\left(\mathrm{C}\right.$ or $\left.\mathrm{N}^{-}\right)$was followed immediately by a nonexcitor ( $\mathrm{T}$ or $\mathrm{L})$; (e) more second-order conditioning in which the $\mathrm{C}_{\text {or }} \mathrm{N}^{-}$that had been paired with the nonexcitatory $\mathrm{T}$ or $\mathrm{L}$ was now paired with the excitatory $\mathrm{T}$ or $\mathrm{L}$; and (f) summation testing in which the two second-order $\mathrm{CSs}\left(\mathrm{C}\right.$ and $\left.\mathrm{N}^{-}\right)$were given alone and in compound.

Preliminary training and differential conditioning. Preliminary training, pretesting, and differential conditioning resembled that of Experiment 1 except that differential conditioning of $\mathrm{T}$ and $\mathrm{L}$ lasted 10 days rather than 8 . The order of trials over days was T L, L T, L T, T L, L T, T L, L T, T L, T L, and L T.

Pretesting following differential conditioning. Differential conditioning was followed by 2 days of further pretesting of $C$ and $\overline{\mathrm{N}}$ The aim was to ensure that fear conditioned to $\mathrm{T}$ or $\mathrm{L}$ had not generalized to $\mathrm{C}$ or $\overline{\mathrm{N}}$ On Day I, C and $\overline{\mathrm{N}}$ began at the start of min 25 and 52, respectively. On Day 2, Nand C began at the start of min 11 and 39, respectively. CSs were 2-min long.

Second-order conditioning: Part 1. Second-order conditioning followed the second pretesting and lasted 8 days. The design provided a within-subject assay of second-order conditioning. Thus, for each rat, one untrained CS $(\mathrm{C}$ or $\overline{\mathrm{N}})$ terminated in the onset of the first-order excitor ( $\mathrm{L}$ or $\mathrm{T}$ ) from differential conditioning. The second untrained CS $(\mathrm{C}$ or $\overline{\mathrm{N}})$ terminated in the onset of the nonexcitatory $\mathrm{CS}$ ( $\mathrm{L}$ or $\mathrm{T})$ from differential conditioning. Only the untrained CS paired with the first-order excitor was expected to gain second-order conditioned strength. On each day of second-order conditioning there were two second-order trials of each type and one shock-reinforced occurrence of the first-order excitor ( $\mathrm{T}$ or $\mathrm{L}$ ) from the differential conditioning phase. During the second-order phase, the duration of all CSs was reduced from 2 min to $30 \mathrm{~s}$. The intent of this reduction was, in part, to minimize extinction of the first-order excitors ( $\mathrm{T}$ or $\mathrm{L}$ ) when they themselves were nonreinforced on secondorder conditioning trials. Trials began at the start of min 11, 20, 31, 41, and 50. CS types were fully counterbalanced. That is, for half of the rats, $\mathrm{C}$ was paired with $\mathrm{T}$, and $\overline{\mathrm{N}}$ was paired with $\mathrm{L}$. For the other half, the reverse was true. For half of each of these groups, $\mathrm{T}$ was excitatory and $\mathrm{L}$ was not. For the other half, the reverse was true. The order of trial types was changed daily, and there were never two trials of the same type given in succession on 1 day.

Second-order conditioning: Part 2. In the previous phase, one untrained stimulus was left neutral by pairing it with a nonexcitatory CS. In the present phase, this neutral stimulus was now paired with a first-order excitor ( $\mathrm{T}$ or $\mathrm{L}$ ) in an effort to establish second-order conditioning to the still neutral stimulus. CSs that had been paired with excitors in the previous phase were not presented here so as to leave their second-order associative values intact. Beginning in this phase, freezing was not scored. That decision was based on weak freezing in the preceding phase. To ensure that the first-order excitors would still be excitatory during second-order conditioning, part 2, we first returned the rats to their original differential conditioning treatments for 2 days.

Summation test. This test was designed to assess the summation of second-order conditioning. It was given over 2 days and involved the presentation of the second-order excitors ( $\mathrm{C}$ and $\mathrm{N}^{-}$) singly and in compound. Summation tests have revealed excitation undetectable by tests of elements in isolation (Hendry, 1982; Reberg, 1972). We performed our summation test in search of such excitation. On Day 1, the order of presentation was $\mathrm{C}, \mathrm{C} \mathrm{N}^{-}$, and $\mathrm{N}^{-}$. On Day 2, the order was reversed. On both days, the CSs began at the start of min 20, 35, and 50. All CSs were 30 -s long. No shocks or first-order excitors were given. 
Direct observations. Beginning on Day 1 of differential conditioning, freezing was scored as in Experiment 1. A single trained observer (Kim) did all of the scoring. On 36\% of the trials during element training, a second trained observer scored concurrently to provide a reliability check. The Pearson product-moment correlation coefficient between the two observers' $p$ (freezing) scores during CS trials was .95. Because Kim scored many more trials than did the other rater, only Kim's data are reported.

Barpress suppression measure. When CS durations were $2 \mathrm{~min}$, we calculated suppression ratios as before. However, when we reduced the CS duration to $30 \mathrm{~s}$ during second-order conditioning, we held the pre-CS period constant at $2 \mathrm{~min}$. Therefore, before computing a suppression ratio as usual, we multiplied the number of responses during the CS by four to correct for the fact that the CS period was four times shorter than the pre-CS period.

\section{Results}

\section{Differential Fear Conditioning}

As shown in Figure 4, the results of differential conditioning resembled in two respects those found in Experiment 1. First, barpress suppression and freezing were acquired only to CSs that were paired with shock $(\mathrm{T}+$ and $\mathrm{L}+)$ and not to CSs that were explicitly unpaired with shock ( $\mathrm{T}-$ and $\mathrm{L}-$ ). Second, by the end of training, $\mathrm{T}+$ and $\mathrm{L}+$ evoked similar barpress suppression, but $\mathrm{T}+$ evoked much more freezing.

Modality $\times$ Measures ANOVAs were conducted separately on freezing and barpress suppression to the reinforced CSs only. For barpress suppression, the only significant effect was the main effect of measures, $F(4,120)=75.49$, suggesting that suppression was acquired by $\mathrm{T}+$ and $\mathrm{L}+$ alike. For freezing, however, the main effect of modality, $F(1,30)=5.47$, and the Modality $\times$ Measure interaction, $F \mathrm{~s}(1,30)=2.90$, indicated that freezing grew more with training to $\mathrm{T}+$ than to $\mathrm{L}+$.

\section{Pretest After Differential Conditioning}

Following differential conditioning, $\mathrm{C}$ and $\overline{\mathrm{N}}$ were again pretested to ensure that they retained their neutrality before undergoing second-order conditioning. Despite extensive pilot data suggesting no generalization among our four CSs, we wished to reassess the possibility that fear might generalize more from the auditory $\mathrm{T}$ to the auditory $\mathrm{C}$ and $\overline{\mathrm{N}}$ than from the visual $\mathrm{L}$ to the auditory $\mathrm{C}$ and $\overline{\mathrm{N}}$. To this end, we looked at the suppression to $\mathrm{C}$ and $\overline{\mathrm{N}}$ during the first $30 \mathrm{~s}$ of each $\mathrm{CS}$ on the first of the 2 pretest days, where we expected any generalized effects to be the clearest. We found that the mean suppression ratio to $\mathrm{C}$ was .42 for rats trained with $\mathrm{T}+$ and $\mathrm{L}-$ and was .48 for rats trained with $\mathrm{T}$ - and $\mathrm{L}+$. The mean suppression ratio to $\overline{\mathrm{N}}$ was .43 in each of those sets of rats. The difference in suppression between the two sets of rats was not significant for either $\mathrm{C}$ or $\overline{\mathrm{N}}$, largest $t(30)=1.91$. Given that the rats had not heard $\mathrm{C}$ or $\overline{\mathrm{N}}$ for 10 days, the weak suppression in the first $30 \mathrm{~s}$ of those stimuli strongly suggests that they had retained their neutrality and provides little evidence that fear generalized more to these cues from $\mathrm{T}+$ than from $\mathrm{L}+$.
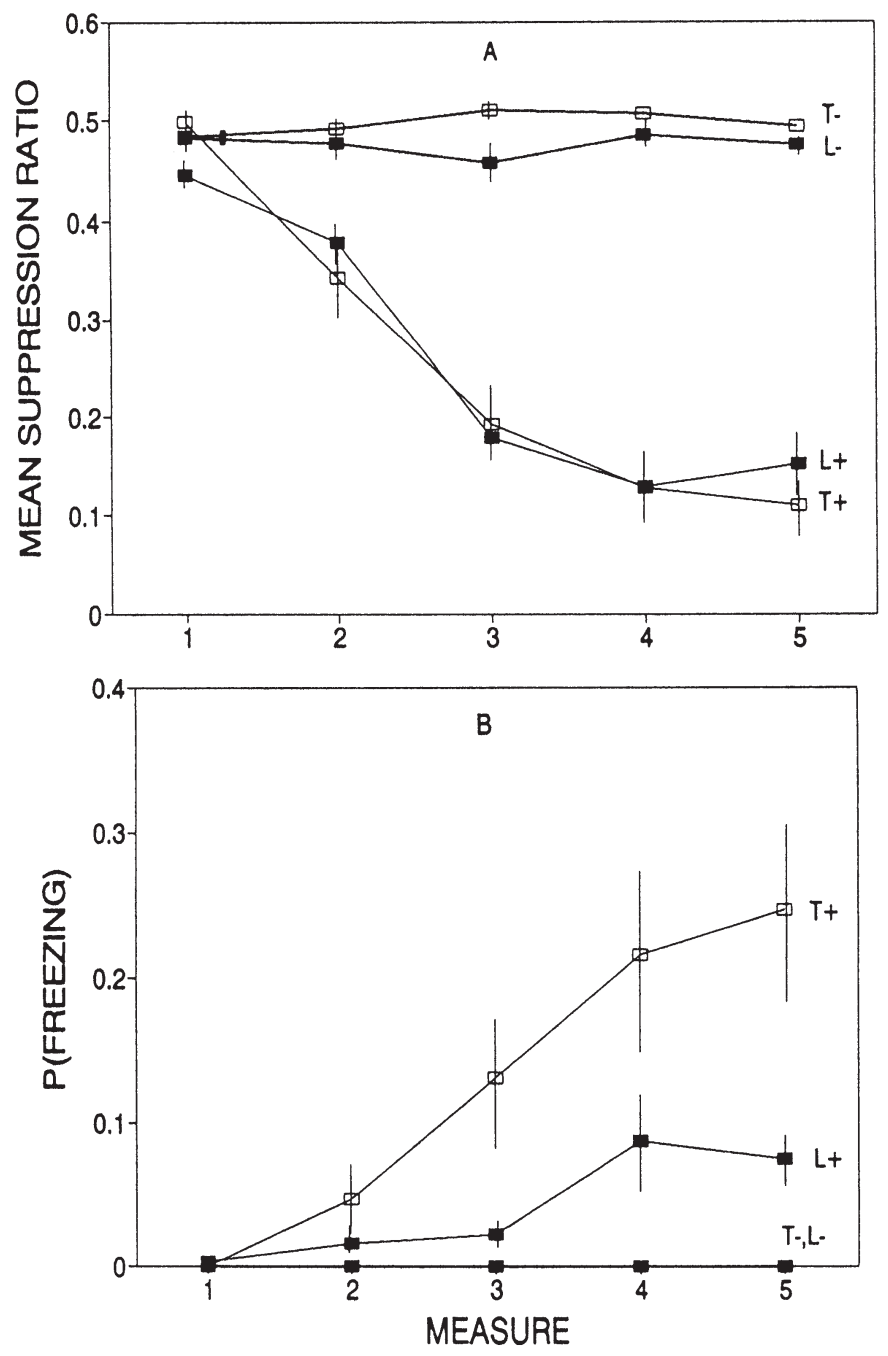

Figure 4. Acquisition of barpress suppression (Panel A) and freezing (Panel B) during differential conditioning in Experiment 2. Measure 1 combines the data from Rats 1-4 of each squad on Day 1 with the data from Rats 5-8 on Day 2. Measure 2 combines the data from Rats 1-4 on Day 3 with the data from Rats $5-8$ on Day 4, and so on. Vertical lines through data points show plus and/or minus one standard error of the mean.

\section{Second-Order Conditioning: Part 1}

During second-order conditioning, barpress suppression increased to $\mathrm{C}$ and $\overline{\mathrm{N}}$ when they were paired with the firstorder excitors ( $\mathrm{T}$ or $\mathrm{L}$ ). On Measure 1, the mean suppression ratio to $C$ and $\bar{N}$ (combined) was .47; on Measure 4, it was .27. However, suppression did not increase to $C$ and $\bar{N}$ when they were paired with the nonexcitors (T or L). On Measure 1, the mean suppression ratio was .46; on Measure 4, it was .48 . Thus, it is clear that the pairing of $\mathrm{C}$ or $\overline{\mathrm{N}}$ with an excitor was necessary for the increase in suppression with training. That increase cannot be nonassociative. These same statements can be made about freezing, although freezing generally was very 
weak. When $\mathrm{C}$ and $\overline{\mathrm{N}}$ were paired with the first-order excitors ( $\mathrm{T}$ or $\mathrm{L}$ ), the mean $p$ (freezing) grew from .01 on Measure 1 to a maximum of .06 on Measure 3. In contrast, $\mathrm{C}$ or $\overline{\mathrm{N}}$ never evoked freezing when these CSs were paired with the nonexcitors ( $\mathrm{T}$ or $\mathrm{L}$ ).

As suggested by Figure SA, the first-order conditioned excitors, $\mathrm{T}$ and $\mathrm{L}$, supported similar second-order conditioning to $\overline{\mathrm{N}}$ but not to $\mathrm{C}$. For $\mathrm{C}$, suppression was acquired only when $\mathrm{T}$ was the reinforcer. A Groups $\times$ Measures ANOVA found significant effects of groups, $F(3,28)=10.66$, and measures, $F(3,84)=26.16$. A second Groups $\times$ Measures ANOVA was performed in which only Groups $\mathrm{C} \rightarrow \mathrm{T}, \overline{\mathrm{N}} \rightarrow \mathrm{T}$, and $\overline{\mathrm{N}} \rightarrow \mathrm{L}$ were included. This ANOVA found only the effects of mea-
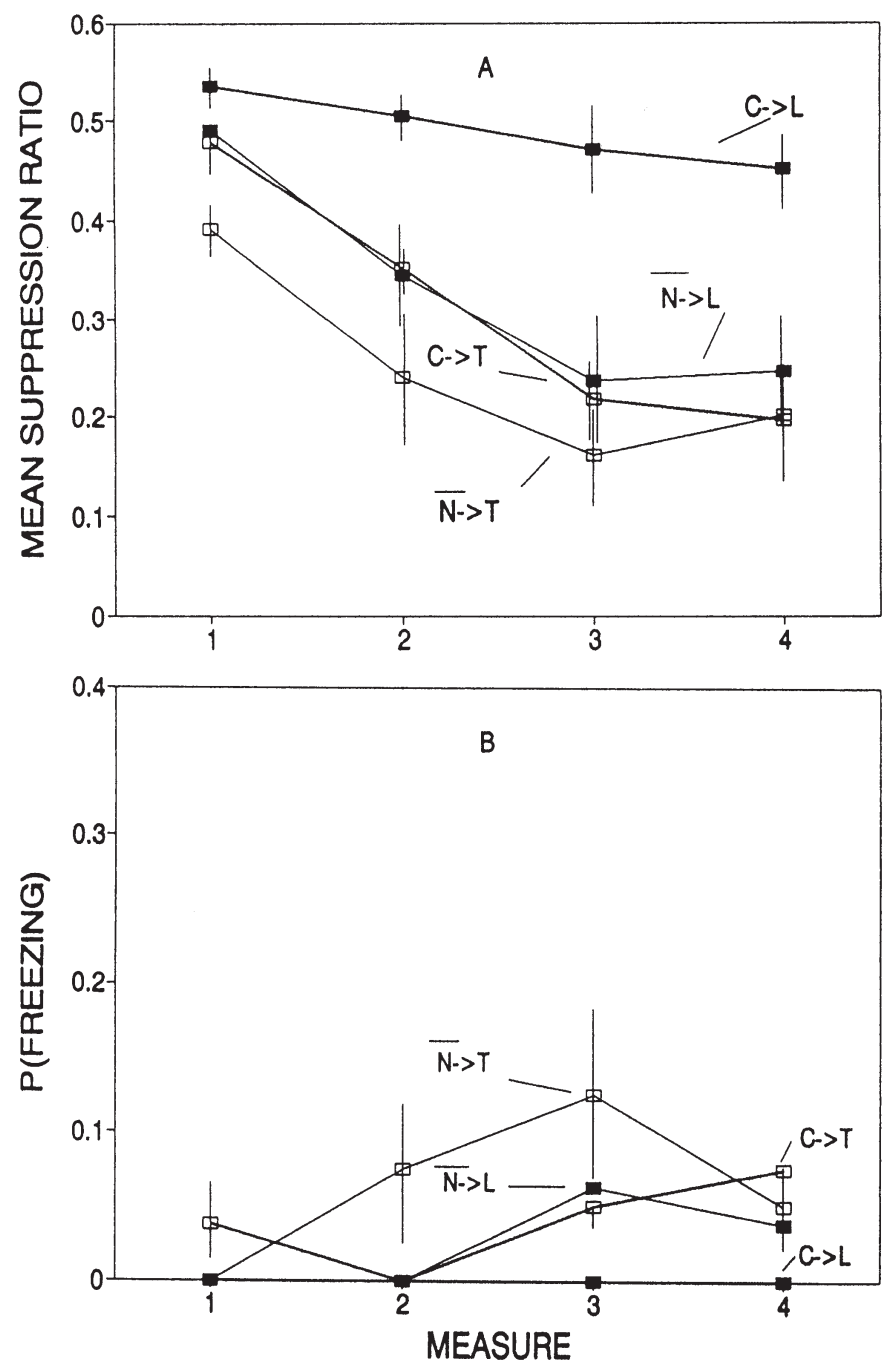

Figure 5. Barpress suppression (Panel A) and freezing (Panel B) to CSs paired with first-order excitors during second-order conditioning, part 1, in Experiment 2. Measure 1 combines the data from Rats 1-4 of each group of 8 rats on Day 1 with the data from Rats 5-8 on Day 2. Measure 2 combines the data from Rats $1-4$ on Day 3 with the data from Rats 5-8 on Day 4, and so on. Responding to stimuli paired with the nonexcitors is not shown (to avoid clutter). Vertical lines through data points show plus and/or minus one standard error of the mean. sures to be significant, $F(3,63)=25.82$, suggesting that these groups behaved alike. A third ANOVA, which included only Groups $\overline{\mathrm{N}} \rightarrow \mathrm{T}$ and $\overline{\mathrm{N}} \rightarrow \mathrm{L}$ also found no effect of groups, $F(1$, $14)=2.05$, or a Groups $\times$ Measures interaction $(\mathrm{F}<1)$. However, a fourth ANOVA pitting Group $\mathrm{C} \rightarrow \mathrm{L}$ against all others combined found significantly weaker suppression in $\mathrm{C} \rightarrow \mathrm{L}$, $F(1,30)=26.94$, and found a significant Groups $\times$ Measures interaction, $F(3,90)=3.68$, reflecting the failure of $\mathrm{C}$ to acquire second-order conditioned strength when reinforced with the excitatory L.

As suggested by Figure 5B, the acquisition of freezing to $\mathrm{C}$ and $\mathrm{N}$ during this same second-order conditioning phase was weak under all conditions. Still, analyses supported the same conclusions as for barpress suppression. A Groups $\times$ Measures ANOVA on the freezing data found a significant effect of measures, $F(3,84)=5.49$, and Groups $\times$ Measures, $F(9,84)=2.37$, suggesting that freezing increased with training and did so more for some groups than for others. A second Groups $\times$ Measures ANOVA including only Groups $\mathrm{C} \rightarrow \mathrm{T}, \mathrm{N}^{-} \rightarrow \mathrm{T}$, and $\mathrm{N}^{-} \rightarrow \mathrm{L}$ found only the effect of measures to be significant, $F(3,63)=5.49$, suggesting that these groups behaved alike. A third ANOVA including only Groups $\mathrm{N}^{-} \rightarrow \mathrm{T}$ and $\mathrm{N}^{-} \rightarrow \mathrm{L}$ also found no effect of groups or the Groups $\times$ Measures interaction $(\mathrm{Fs}<1.18)$. However, a third ANOVA that contrasted Group $\mathrm{C} \rightarrow \mathrm{L}$ against all other groups combined found $F(1,30)=3.89, p<.06$, for the effect of groups. This result, again, suggests a failure of $\mathrm{C}$ to acquire second-order conditioned strength when reinforced with the excitatory L.

During second-order conditioning, part 1, the pattern of suppression and freezing to the first-order excitors when presented in the absence of $\mathrm{C}$ or $\overline{\mathrm{N}}$ resembled that seen at the end of differential conditioning. That is, averaged over all four measures, there was more freezing to $\mathrm{T}$ than to $\mathrm{L}$ (mean $p$ [freezing] $=.14$ and .03 , respectively), $F(1,30)=8.34$; however, barpress suppression was similar to the two CSs $(M \mathrm{~s}=$ .13 and .15 to $\mathrm{T}$ and $\mathrm{L}$, respectively; $F<1$ ). The endurance of this data pattern despite the reduction in CS duration from 120 to $30 \mathrm{~s}$ and despite the intermixing of second-order conditioning trials suggests that it is robust.

\section{Second-Order Conditioning: Part 2}

In the previous phase, second-order conditioning in Group $\mathrm{C} \rightarrow \mathrm{L}$ was weak versus that in the other three groups. We now asked if that weak conditioning could have reflected a sampling error. In the present phase, Group $\overline{\mathrm{N}} \rightarrow \mathrm{L}$ from the previous phase now received $\mathrm{C} \rightarrow \mathrm{L}$. If this group also showed weak second-order conditioning to $\mathrm{C}$ when $\mathrm{C}$ was reinforced by the excitatory $\mathrm{L}$, then a sampling error would seem unlikely. Instead, it would appear that L does not support much second-order conditioning to C. The results plotted in Figure 6 contrast the suppression in the new Group $\mathrm{C} \rightarrow \mathrm{L}$ with that in the remaining three groups combined. The plots suggest that, once again, the first-order excitor, L, failed to reinforce second-order conditioning to C. A Groups $\times$ Measures ANOVA 


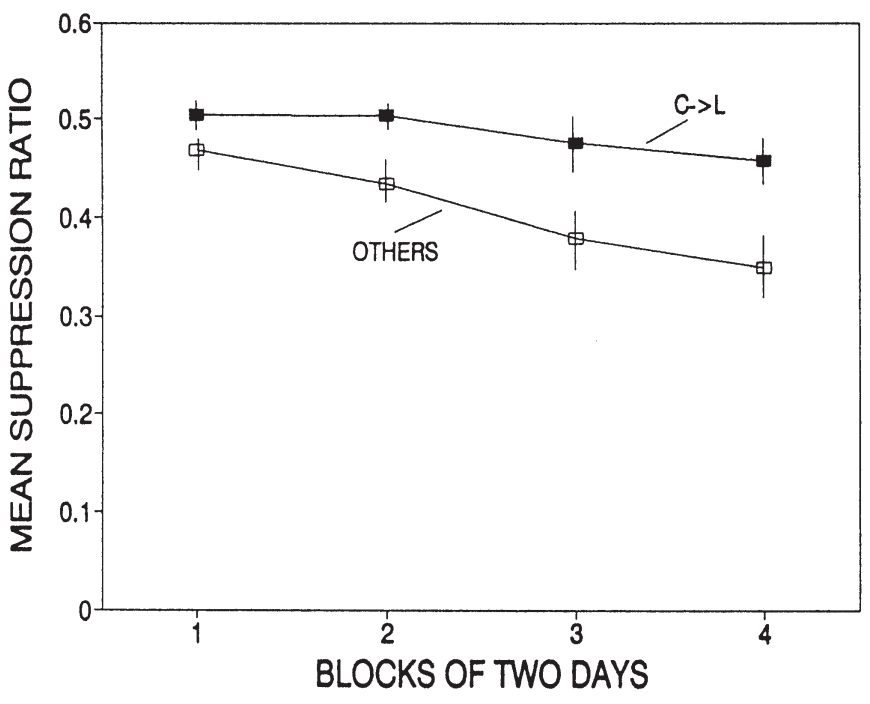

Figure 6. Acquisition of barpress suppression during second-order conditioning, part 2, in Experiment 2. Vertical lines through data points show plus and/or minus one standard error of the mean.

of the data in Figure 6 found $F(1,30)=3.78, p=.06$, for the effect of groups. This result suggests that the weak second-order conditioning in Group $\mathrm{C} \rightarrow \mathrm{L}$ in the previous phase was not due to a sampling error but instead reflected the inability of the excitatory L to support second-order conditioning to C. It is notable that in this phase, second-order conditioning appeared to be weaker in general than it was in the preceding phase (compare Figures 6 and 5). This result was not unexpected, and it probably reflects the nonreinforced preexposure that CSs to be conditioned in the present phase had received in the previous phase (Lubow, 1989).

During second-order conditioning, part 2, freezing was not scored. However, barpress suppression to the first-order excitors remained strong and similar to $\mathrm{T}$ and $\mathrm{L}$ (both $M \mathrm{~s}=$ $13 ; F<1)$.

\section{Summation Test}

Figure 7 shows the results of the summation test. The data plotted are the means of the 2 days of testing. The left panel shows suppression to $C, \overline{\mathrm{N}}$, and to the $\overline{\mathrm{N}}$ compound after $\mathrm{C}$ and $\overline{\mathrm{N}}$ had been paired with a $\mathrm{T}$ excitor. The panel shows more suppression to the compound than to $\mathrm{C}$ alone or to $\overline{\mathrm{N}}$ alone, $t \mathrm{~s}(15)>2.78$. The right panel shows suppression to the same cues after $\mathrm{C}$ and $\overline{\mathrm{N}}$ had been paired with an L excitor. Here suppression was stronger to the compound than to $\mathrm{C}$ alone, $t(15)=3.95$, but not to $\overline{\mathrm{N}}$ alone. The results in the left panel would be expected if both elements had acquired second-order excitatory strength: Their independent effects should summate. The results in the right panel would be expected if $\mathrm{C}$ failed to acquire second-order strength when reinforced by L. If $\mathrm{C}$ had no excitatory value, then there could be no summation. Thus the results of the summation test conform with those of second-order conditioning, parts 1 and 2, which suggested that $\mathrm{C}$ failed to acquire much second-order conditioned strength when reinforced by $\mathrm{L}$.

\section{Pre-CS Responding}

Groups $\times$ Measure ANOVAs similar to those conducted on the barpress suppression data were conducted separately on the pre-CS response rates during second-order conditioning, parts 1 and 2. These ANOVAs revealed no significant effects, suggesting that differences in the pre-CS rates did not taint the barpress suppression data in these focal phases. In each of these phases, the mean pre-CS rate was 27 responses per min. Freezing during pre-CS periods of secondorder conditioning was nonexistent.

\section{Discussion}

In Experiment 2, the first-order excitors, $\mathrm{T}$ and $\mathrm{L}$, supported similar second-order conditioning to the untrained $\mathrm{N}^{-}$ $\mathrm{CS}$. This result suggests that $\mathrm{T}$ and $\mathrm{L}$ had previously acquired similar conditioned value, even though $\mathrm{T}$ evoked more freezing than did L. Thus, despite their similar values, the two CSs evoked CRs of different forms: strong freezing to $\mathrm{T}$ and weak freezing to L. It also appears from this result that the barpress suppression measure during differential fear conditioning more accurately assessed the conditioned value of $\mathrm{T}$ and $\mathrm{L}$ than did the freezing measure. These conclusions are entirely congruent with those drawn from the results of Experiment 1 . There, $\mathrm{L}$ was shown to be at least as effective as $\mathrm{T}$ at blocking conditioning to a third stimulus. Together, the blocking results and the second-order conditioning results suggest that in fear conditioning, as in appetitive conditioning (Holland, 1977), the nature of the CS is a determinant of the form of the Pavlovian CR.

Although $\mathrm{T}$ and $\mathrm{L}$ supported similar second-order conditioning to $\overline{\mathrm{N}}$ in Experiment 2, they did not support similar second-order conditioning to $\mathrm{C}$. For the $\mathrm{C}$ stimulus, $\mathrm{L}$ was a weak reinforcer, but $\mathrm{T}$ was highly potent. This result contradicts the conclusions drawn in the preceding paragraph. It implies that the reason $\mathrm{L}$ evokes less freezing than $\mathrm{T}$ is that $\mathrm{L}$ is poorly conditioned. That conclusion, of course, is inconsistent with the blocking results of Experiment 1, the results of second-order conditioning to $\overline{\mathrm{N}}$ in Experiment 2, and with the results of overconditioning to be presented in Experiment 3. We are inclined, therefore, to view results of second-order conditioning to $\mathrm{C}$ as anomalous and to search for an explanation in terms of some oddity in the $\mathrm{C} \rightarrow \mathrm{L}$ sequence. As to what that oddity might be, we can only make the following post hoc observation. There were four stimulus sequences used in Experiment 2: $\overline{\mathrm{N}} \rightarrow \mathrm{T}, \overline{\mathrm{N}} \rightarrow \mathrm{L}, \mathrm{C} \rightarrow \mathrm{T}$, and $\mathrm{C} \rightarrow \mathrm{L}$. Of these four, the $\mathrm{C} \rightarrow \mathrm{L}$ sequence was the only one in which the reinforcer was accompanied by a decrease in sound level. For every other sequence, the reinforcer was accompanied by an increase in sound level $(\overline{\mathrm{N}} \rightarrow \mathrm{T}$ and $\overline{\mathrm{N}} \rightarrow \mathrm{L})$ or was itself louder than the stimulus it followed $(\mathrm{C} \rightarrow \mathrm{T})$. Davis (1974) has shown that 


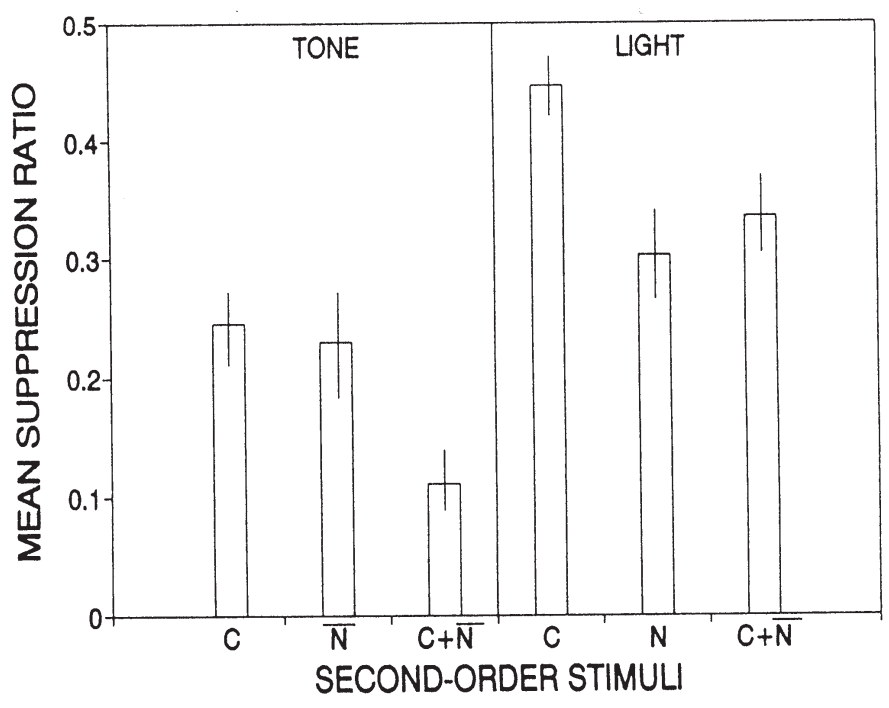

Figure 7. Summation test of second-order CSs in Experiment 2. Vertical lines through data points show plus and/or minus one standard error of the mean.

when a $110-\mathrm{dB}$ tone is repeatedly presented against a white noise background, responding to the tone is sensitized in an $80-\mathrm{dB}$ background but is habituated in a $60-\mathrm{dB}$ background. perhaps in Experiment 2, the increase in sound level following the first element of the sequence had a sensitizing effect, enhancing the effectiveness of reinforcement. This effect would not operate for the $\mathrm{C} \rightarrow \mathrm{L}$ sequence. Indeed, if anything, the opposite should hold.

\section{Experiment 3: Overconditioning}

After 10 days of differential conditioning (element training) in Experiment 2, $\mathrm{T}$ evoked more freezing than did $\mathrm{L}$. Could it be that with more extensive training, freezing to $\mathrm{L}$ would catch up with freezing to T? To find out, we extended element training in Experiment 3 to 16 days (eight measures). A second reason for extending this training was to ensure asymptotic conditioning to $\mathrm{T}$ and $\mathrm{L}$. When two elements are conditioned separately to asymptote and then are reinforced in compound, it is predicted that each will lose conditioned value (Rescorla \& Wagner, 1972). Rescorla (1970) termed this procedure overconditioning and found evidence for the prediction. In our case, we might expect $\mathrm{T}$ and $\mathrm{L}$ to lose similar degrees of control over barpress suppression as a result of overconditioning. However, only $\mathrm{T}$ should lose substantial control over freezing because L's control over freezing is weak anyway. According to the theory, any loss of control by $\mathrm{T}$ should be directly proportional to L's value. If $\mathrm{L}$ has little value, as suggested by the weak freezing it evokes, then T's loss as a result of overconditioning cannot be appreciable.

To test this prediction, we gave one group of rats (Group $\mathrm{t}-\mathrm{t}$ ) conditioning to the target $(\mathrm{t})$ elements $(\mathrm{T}$ and $\mathrm{L}$ ) singly and then reinforced those elements in compound. (The letter $\mathrm{t}$ before the dash in the group name denotes that target elements were conditioned during element training, and the letter $t$ after the dash denotes that target elements were conditioned later in compound.) Comparison of responding evoked by $\mathrm{T}$ and $\mathrm{L}$ after compound conditioning with responding evoked just before compound conditioning would provide a withinsubject measure of the ability of overconditioning to weaken the value of those target elements. To control for the passage of time and for US habituation during compound conditioning, we gave a second group (Group $\mathrm{t}-\mathrm{n}$ ) compound conditioning to nontarget (n) elements $(\mathrm{C}$ and $\overline{\mathrm{N}})$ after first reinforcing the target elements in isolation. Comparison of responding to the target elements after compound conditioning in Groups $\mathrm{t}-\mathrm{t}$ and $\mathrm{t}-\mathrm{n}$ would provide a between-groups measure of the ability of overconditioning to weaken the value of the elements in Group t-t. The groups would be equated for passage of time since element conditioning and number of USs during compound conditioning. To determine the level of responding to the target elements following conditioning to the compound in the absence of any previous conditioning to its constituent elements, we gave a third group (Group $\mathrm{n}-\mathrm{t}$ ) compound conditioning to the target elements following element conditioning to the nontarget elements. This group was thus equated with Group $\mathrm{t}-\mathrm{t}$ in terms of number of reinforced trials with the target elements in compound and in terms of any previous US habituation; however, Group $n-t$ did not receive conditioning to the target elements in isolation before training of those elements in compound. According to the Rescorla and Wagner model, a US can support only so much conditioning, an amount termed lambda $(\lambda)$. A well-known prediction of the model is that if two elements (such as T and L) are conditioned in compound (as in Groups $n-t$ and $t-t$ ), the sum of their values at the end of that training should approach $\lambda$, assuming an adequate number of compound trials. However, for Group $\mathrm{t}-\mathrm{n}$, in which the target elements are conditioned singly, the sum of the values of $\mathrm{T}$ and $\mathrm{L}$ should approximate $2 \lambda$. This means that in the test of the elements after the present compound conditioning phase, the mean response to $\mathrm{T}$ and $\mathrm{L}$ in Group $\mathrm{t}-\mathrm{t}$ should be similar to that in Group $\mathrm{n}-\mathrm{t}$ and weaker than that in Group $\mathrm{t}-\mathrm{n}$.

An added point of interest in Experiment 3 is the responding controlled (in Group $\mathrm{n}-\mathrm{t}$ ) by the nontarget elements ( $\overline{\mathrm{N}}$ and C) during element training. In previous work comparing responding to auditory versus visual stimuli, the auditory stimuli have been limited to tone and white noise. Whether other auditory stimuli, such as $\overline{\mathrm{N}}$ and $\mathrm{C}$, evoke more freezing than light while evoking similar levels of barpress suppression remains to be seen.

\section{Method}

\section{Subjects}

The subjects were 12 male and 12 female experimentally naive albino rats bred in our colony from Holtzman stock. Free-feeding weights ranged from 281 to $360 \mathrm{~g}$ in the female rats and from 461 to 
$580 \mathrm{~g}$ in the male rats. These weights were lowered $20 \%$ before the experiment and were kept at that level. The colony was lighted on a 16:8 hr light:dark cycle. Experimental sessions occurred during the light part of the cycle.

\section{Apparatus}

The apparatus was unchanged.

\section{Procedure}

The procedure had the following four phases: (a) preliminary training designed to condition barpressing and to pretest T, L, C, and NCSs; (b) element conditioning designed to condition fear separately to $\mathrm{T}$ and $\mathrm{L}$ for some rats and to $\mathrm{C}$ and $\overline{\mathrm{N}}$ for other rats; (c) compound conditioning to either TL or to $\overline{\mathbb{Q}}$ and (d) extinction testing to $\mathrm{T}$ and $\mathrm{L}$.

Preliminary training and element conditioning. Preliminary training and pretesting resembled that of Experiments 1 and 2. Element training resembled the differential conditioning in those experiments except that two elements were reinforced separately in each of 16 daily sessions. During this phase, the rats were assigned to three groups, each with four male and four female rats. Groups $t-t$ and $t-$ $\mathrm{n}$ received element conditioning with the target $(\mathrm{t})$ elements ( $\mathrm{T}$ and L). Group n-t received element conditioning to the nontarget (n) elements $(\mathrm{C}$ and $\mathrm{N})$. For Groups $\mathrm{t}-\mathrm{t}$ and $\mathrm{t}-\mathrm{n}$, the order of reinforced elements over the 16 days was T L, L T, L T, T L, L T, T L, L T, T L, T L, L T, L T, T L, L T, T L, L T, and T L. For Group n-t, C replaced T, and $\bar{N}$ replaced L. In this phase and in the remaining phases, the start time of each 2-min element varied daily.

Compound conditioning. Two reinforced compound CSs were given over each of the next 8 days. For Groups $\mathrm{t}-\mathrm{t}$ and $\mathrm{n}-\mathrm{t}$, the target elements ( $T$ and $L$ ) were reinforced in compound. For Group $t-n$, the nontarget elements $(\mathrm{C}$ and $\overline{\mathrm{N}})$ were reinforced in compound.

Target element testing. On each of the next 4 days, each target element was given once without shock. The order of trials over days was T L, L T, L T, and T L.

Direct observations. All of the trials were scored for freezing by a trained observer (Bevins). Beginning on Day 6 of element training, a second observer also scored $87 \%$ of the remaining trials. The Pearson product-moment correlation between their $p$ (freezing) scores was .94. Because Bevins scored many more trials than did the other rater, only Bevins's data are reported.

\section{Results}

\section{Element Training}

Of primary interest is the responding to the target elements, $\mathrm{T}$ and L. Figure 8 shows that the response pattern resembled that described in Experiments 1 and 2. That is, T and L came to evoke similar levels of barpress suppression at the same time that $\mathrm{T}$ evoked much more freezing than did L. Even after extensive training, freezing to $\mathrm{L}$ showed no tendency to catch up with freezing to T. Both barpress suppression and freezing to $\mathrm{T}$ and $\mathrm{L}$ appeared to be asymptotic. Of secondary interest is the responding to the nontarget elements $(\bar{N}$ and $\mathrm{C})$. Here, the response pattern was less remarkable: $\overline{\mathrm{N}}$ evoked much more freezing than did $\mathrm{L}$, but $\mathrm{C}$ did not. These results are not surprising because $\overline{\mathrm{N}}$ also evoked more barpress suppression, but $\mathrm{C}$ did not.

These descriptions were supported by statistical analyses. A Modality (T vs. L) $\times$ Measure ANOVA on the suppres-
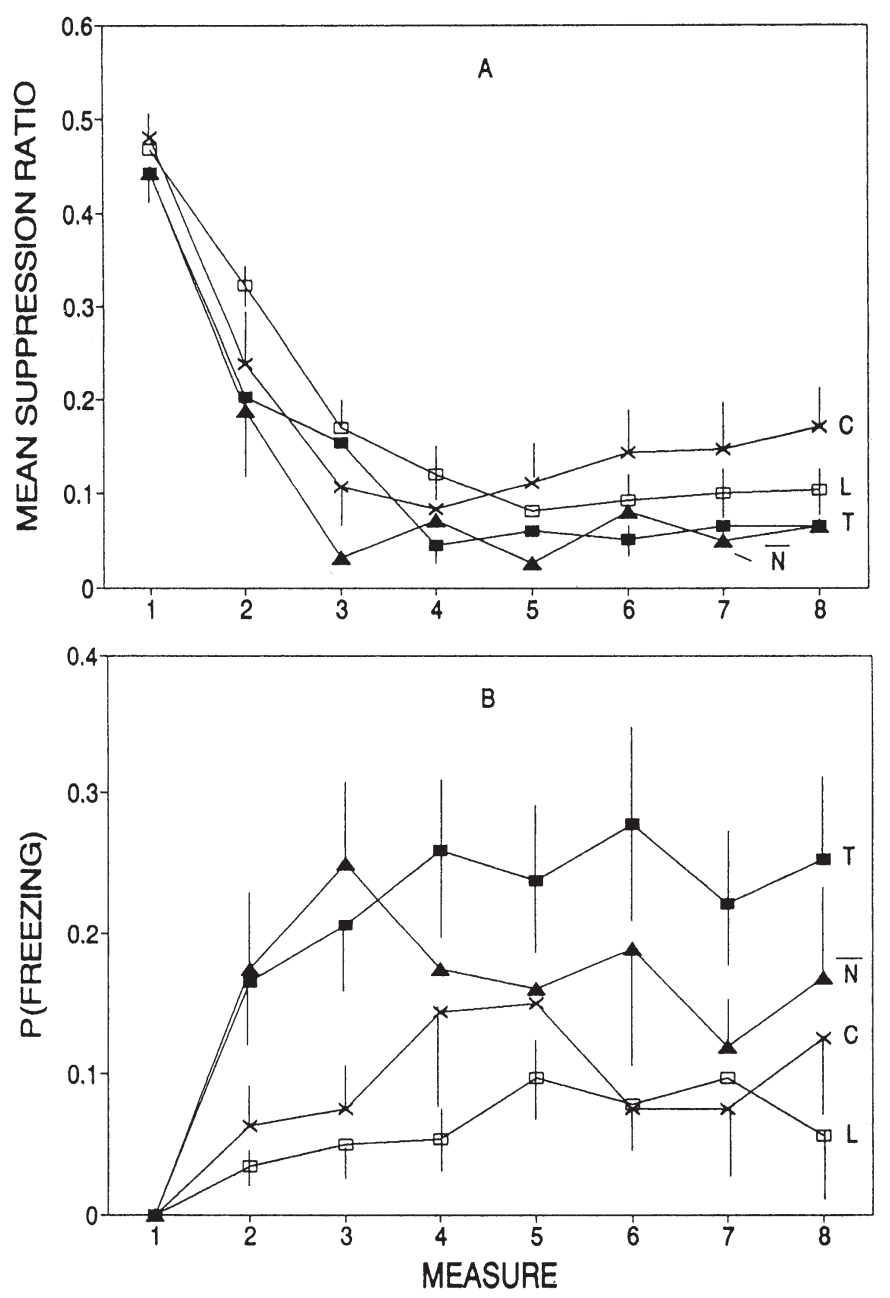

Figure 8. Acquisition of barpress suppression (Panel A) and freezing (Panel B) during element training in Experiment 3. Measure 1 combines the data from Rats 1-4 of each squad on Day 1 with the data from Rats 5- 8 on Day 2. Measure 2 combines the data from Rats 14 on Day 3 with the data from Rats $5-8$ on Day 4, and so on. Vertical lines through data points show plus and/or minus one standard error of the mean.

sion data found a main effect of modality, $F(1,15)=7.13$, and measure, $F(7,105)=62.6$, and no interaction. However, the effect of modality was due mainly to the divergence of $\mathrm{T}$ and $\mathrm{L}$ performance early in training. On none of the last four measures was the difference between $\mathrm{T}$ and $\mathrm{L}$ significant, $F \mathrm{~s}(1,15)<1.61$. A similar ANOVA on the freezing data found significant effects of modality, $F(1,15)=35.32$, and both the effects of measure and Modality $\times$ Measure were significant, $F \mathrm{~s}(7,105)>2.99$. Separate ANOVAs $(\overline{\mathrm{N}}$-vs. $-\mathrm{L} \times$ Measure and C-vs.-L $\times$ Measure) found more barpress suppression and freezing to $\overline{\mathrm{N}}$ than to $\mathrm{L}, F_{\mathrm{S}}(1,22)>5.19$, but similar barpress suppression and freezing to $\mathrm{C}$ and $\mathrm{L}\left(F_{\mathrm{S}}<1\right)$.

\section{Compound Conditioning}

As shown in Figure 9, barpress suppression and freezing during compound conditioning were both initially strong only 

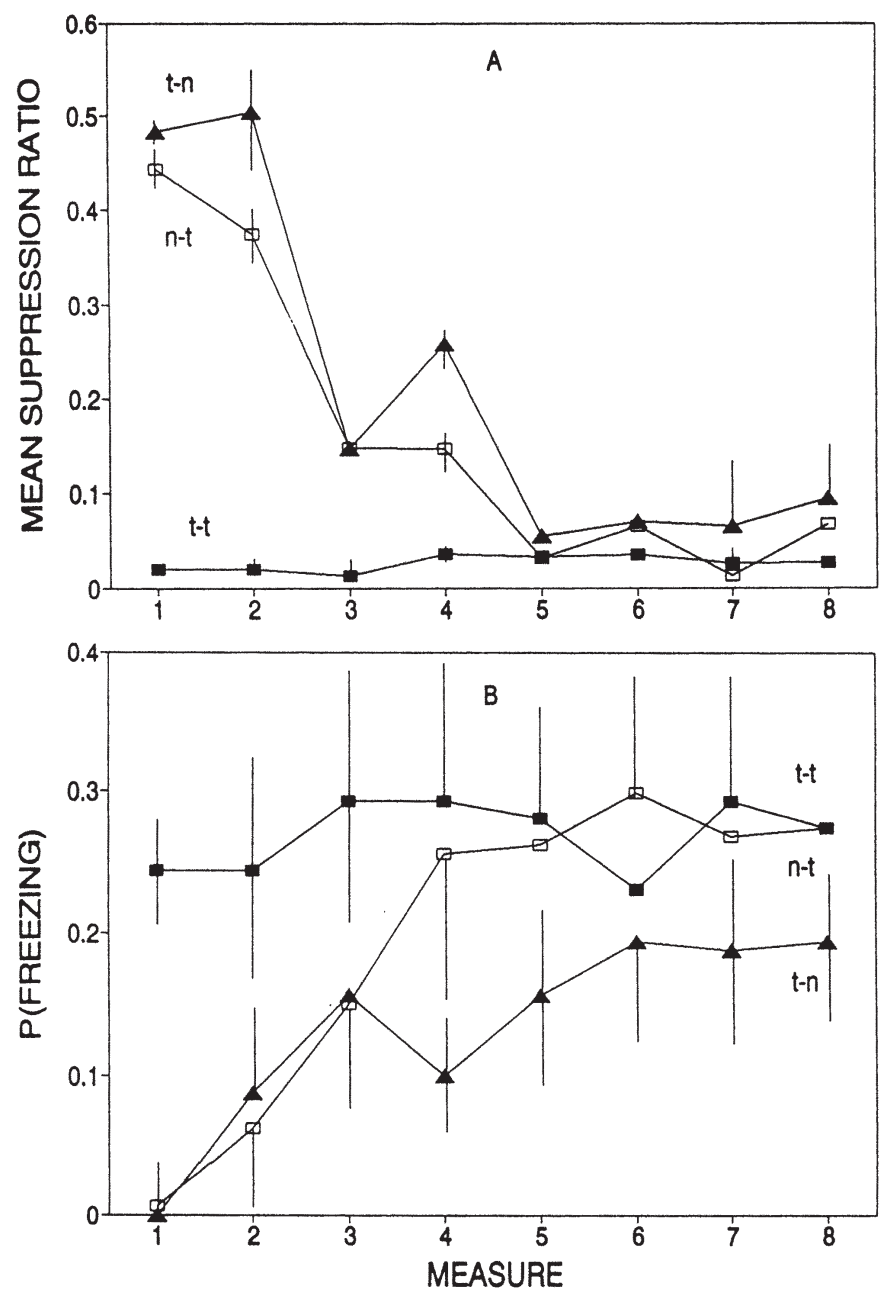

Figure 9. Barpress suppression (Panel A) and freezing (Panel B) during compound conditioning of Experiment 3. Measure 1 combines the data from Rats 1-4 of each squad on Day 1 with the data from Rats 5-8 on Day 2. Measure 2 combines the data from Rats 1-4 on Day 3 with the data from Rats $5-8$ on Day 4 , and so on. Vertical lines through data points show plus and/or minus one standard error of the mean.

to compounds containing elements previously reinforced. Of main interest is the fact that Group $\mathrm{t}-\mathrm{t}$ suppressed more to the TL compound on Measure $1(M=.02$; see Figure 9A) than to either T or L $(M \mathrm{~s}=.09$ and .11, respectively; see Figure 8A) on the last measure of element training, $t \mathrm{~s}(1,7)>3.24$. This summation effect means that during element training there was room for $\mathrm{T}$ to evoke more suppression than $\mathrm{L}$ if indeed T had the greater value (cf. Bevins \& Ayres, 1991). In contrast to the suppression data, the freezing data did not show a summation effect. Freezing to the compound in Group $\mathrm{t}-\mathrm{t}$ ( $M$ $=.24$; see Figure 9B) did not exceed freezing to the T element $(M=.26$; see Figure 8B).

\section{Element Testing}

The central observation in the element test was that overconditioning appeared to weaken barpress suppression to both $\mathrm{T}$ and $\mathrm{L}$ but weakened freezing only to $\mathrm{T}$. This was the data pattern predicted from the Rescorla and Wagner (1972) model under the assumption that element training endowed $\mathrm{T}$ and $\mathrm{L}$ with similar conditioned values, despite the differences in freezing that $\mathrm{T}$ and $\mathrm{L}$ evoked. The evidence for these assertions is shown in Figure 10.

Figure 10A shows the barpress suppression to the target elements during the last measure of element training (Measure 8) and the first measure of element testing (Measure 1). Figure 10B shows the freezing. In each panel, the first pair of bars shows the
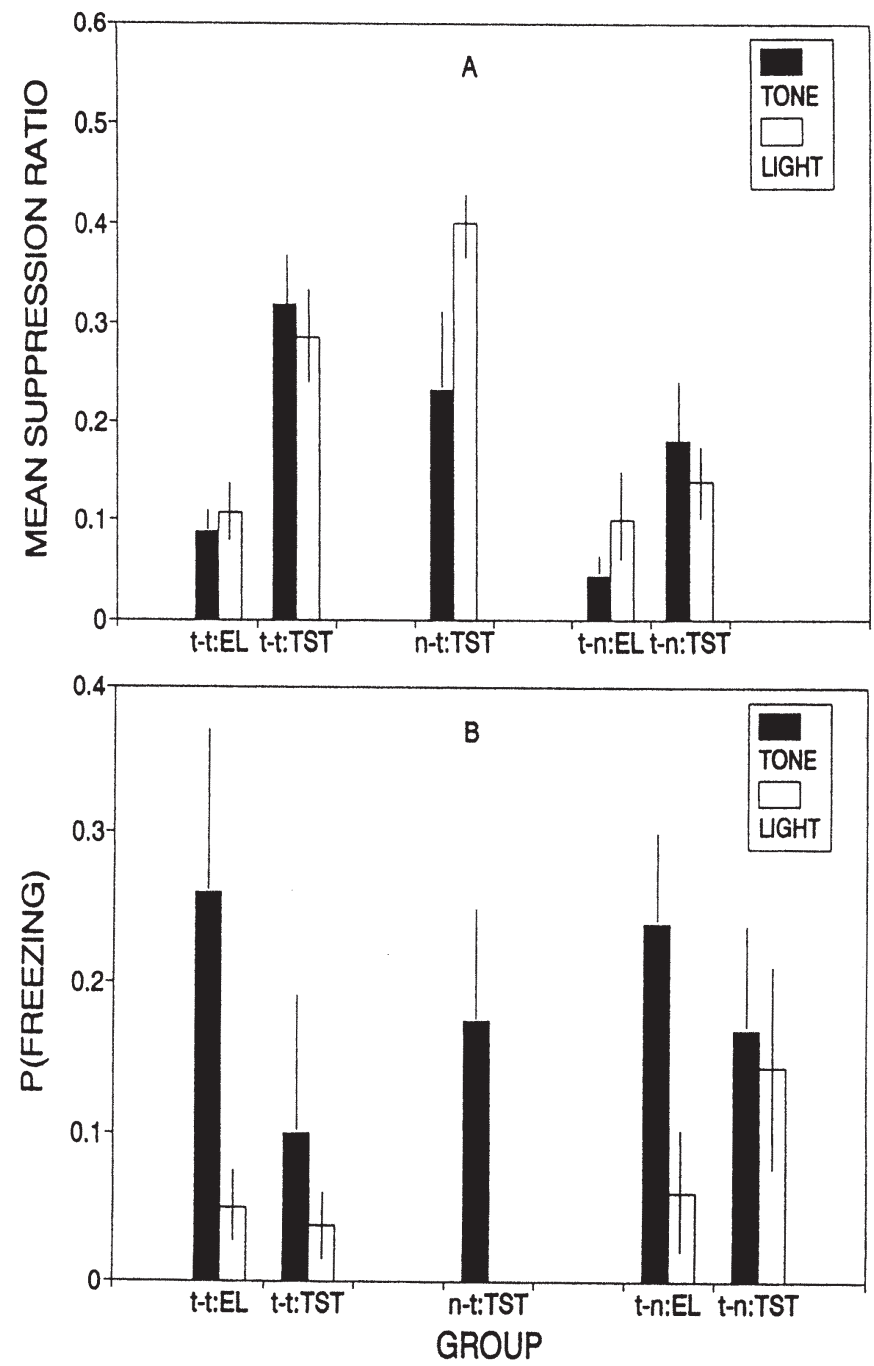

Figure 10. Barpress suppression (Panel A) and freezing (Panel B) on the last measure of element training (Measure 8) and the first measure of element testing (Measure 1) in Experiment 3. Vertical lines through data points show plus and/or minus one standard error of the mean. There is no open bar in Figure 10B for Group n-t in the test (TST) because the mean freezing to light in that group was zero. 
response of Group $\mathrm{t}-\mathrm{t}$ during element training (EL). The second pair shows the response of Group $\mathrm{t}-\mathrm{t}$ in the test (TST). For Group $\mathrm{n}-\mathrm{t}$, there are no bars for element training because this group did not receive element training with the target elements.

Assuming that $\mathrm{T}$ and $\mathrm{L}$ have similar conditioned values (because they evoke similar barpress suppression), the Rescorla and Wagner model predicts that they should lose similar control over barpress suppression as a result of overconditioning. The left two pairs of bars in Figure 10A suggest that the loss was similar indeed. The model also predicts that after compound conditioning, the sum of the values of $\mathrm{T}$ and L should approximate A in both Group $\mathrm{t}-\mathrm{t}$ and Group $\mathrm{n}-\mathrm{t}$ but should approximate 2A in Group $\mathrm{t}-\mathrm{n}$. The data in Figure 10A appear consistent with that prediction as well: The second and third pair of bars suggest similar mean responding to $\mathrm{T}$ and $\mathrm{L}$ in Groups $\mathrm{t}-\mathrm{t}$ and $\mathrm{n}-\mathrm{t}(\mathrm{Ms}=.30$ and 32, respectively), which in turn is weaker than the mean responding $(M=.16)$ to $\mathrm{T}$ and $\mathrm{L}$ in Group $\mathrm{t}-\mathrm{n}$ (rightmost pair of bars).

Statistical analyses supported these descriptions. A Group $(\mathrm{t}-\mathrm{t}$ vs. $\mathrm{t}-\mathrm{n}) \times$ Phase (element training [Measure 8] vs. element testing [Measure 1]) $\times$ Modality (T vs. L) ANOVA found the effects of phase and Groups $\times$ Phase to be significant, $F_{\mathrm{S}}(1$, 14) $>$ 5.93. These effects mean that suppression weakened between element training and testing and did so more for the group that received overconditioning (Group $t-t$ ) than for the group that controlled for the passage of time (Group $t-n)$. The effects of modality and the Groups $\times$ Modality interaction did not approach significance $(F \mathrm{~s}<1)$, suggesting that for both groups the loss of value to $\mathrm{T}$ and $\mathrm{L}$ was similar.

A second ANOVA was performed on only the test suppression of the three groups. This ANOVA found a significant effect of groups, $F(2,21)=3.99$. Planned orthogonal comparisons showed that the mean suppression to $\mathrm{T}$ and $\mathrm{L}$ in Group $\mathrm{t}-\mathrm{t}$ was similar to that in Group $\mathrm{n}-\mathrm{t}(F<1)$ but was weaker in these two groups combined than in Group $\mathrm{t}-\mathrm{n}$, $F(1,21)=7.95$. The ANOVA also yielded $F(2,21)=3.26$, $p<.06$, for the Groups $\times$ Modality interaction, reflecting the fact that only Group n-t suppressed less in testing to $\mathrm{L}$ than to $\mathrm{T}, F(1,21)=6.50$. This result means that when $\mathrm{T}$ and $\mathrm{L}$ were conditioned in compound without first being conditioned singly, T overshadowed L.

Because L controls only weak freezing when conditioned in isolation, the Rescorla and Wagner model cannot expect overconditioning to weaken freezing to $\mathrm{L}$ to any great extent. However, assuming that L has strong conditioned value (as suggested by the barpress suppression it evokes), the model does expect overconditioning to weaken freezing to L's companion, T. Figure 10B appears to confirm this prediction. The two leftmost solid bars suggest that freezing to $\mathrm{T}$ did weaken as a result of overconditioning in Group $\mathrm{t}-\mathrm{t}$. The model also predicts that after compound conditioning, the sum of the values of T and L should approach A in both Group $\mathrm{t}-\mathrm{t}$ and Group $n-t$ but should approach $2 \mathrm{~A}$ in Group $\mathrm{t}-\mathrm{n}$. Figure 10B does not suggest strong evidence for this prediction.
A Group ( $\mathrm{t}-\mathrm{t}$ vs. $\mathrm{t}-\mathrm{n}) \times$ Phase (element training [Measure 8] vs. element testing [Measure 1]) ANOVA performed on freezing only to $\mathrm{T}$ failed to show a significant interaction between groups and phase. Nevertheless, planned t tests using the appropriate error term from the ANOVA showed that the reduced freezing to $\mathrm{T}$ resulting from compound training was significant only in Group $\mathrm{t}-\mathrm{t}, t(14)=3.17$, and not in Group t$\mathrm{n}, t(14)=1.46$. A second ANOVA was conducted on only the test freezing of the three groups and was followed by orthogonal comparisons like those described earlier for barpress suppression. As predicted by the Rescorla and Wagner model, the mean freezing during testing to $\mathrm{T}$ and $\mathrm{L}$ combined was similar in Groups $\mathrm{t}-\mathrm{t}$ and $\mathrm{n}-\mathrm{t}$ ( $M \mathrm{~s}=.07$ and .09 , respectively) and was less than that in Group $\mathrm{t}-\mathrm{n}(M=.16)$. However, the difference was not significant. (Note: For Group n-t, there was no freezing to L, hence the missing open bar in Figure 10B.)

\section{Pre-CS Responding}

Analyses of pre-CS rates corresponding to those conducted on suppression ratios revealed no complications except in the final extinction test. Here, Group $\mathrm{t}-\mathrm{t}$ ( $M=47$ responses per min) responded faster than did the other two groups ( $M \mathrm{~s}=27$ responses per min). This problem seems minor in that most of the comparisons of interest in terms of barpress suppression were withingroup comparisons. In addition, to see if there was any correlation between pre-CS rate and barpress suppression, we computed Pearson product-moment correlation coefficients between mean pre-CS responding to $\mathrm{T}$ and $\mathrm{L}$ in the extinction test and mean suppression to those cues for each group singly and for all three groups together. We then did the same for each CS (T or L) separately. None of these correlations was significant, suggesting little basis for concern about the difference in the pre-CS rates of the three groups. In addition, as before, the results were uncomplicated by pre-CS freezing, which was nonexistent in compound training and extinction testing and which occurred on fewer than $0.2 \%$ of the samples taken during element training.

\section{Discussion}

Four results of Experiment 3 bear directly on the issue of whether the nature of the CS is a determinant of CR form in Pavlovian fear conditioning.

First, even after extensive conditioning to the $\mathrm{T}$ and $\mathrm{L}$ elements, freezing to $\mathrm{L}$ never caught up with freezing to T. Thus the ability of $\mathrm{T}$ and $\mathrm{L}$ to evoke behaviors of different forms does not appear to be a preasymptotic effect. Moreover, if the greater freezing to $\mathrm{T}$ were due only to T's greater salience, then one might expect that L would indeed catch up with $\mathrm{T}$ at asymptote (Rescorla \& Wagner, 1972). (In the Rescorla and Wagner model, at least, salience affects only the rate of approach to asymptote, not the asymptote itself.) The fact that this did not happen suggests that a difference in salience is not the main cause of the difference in freezing. 
Second, after element conditioning, barpress suppression was greater to the compound of $\mathrm{T}$ and $\mathrm{L}$ than it had been to $\mathrm{T}$ and $\mathrm{L}$ elements. This result resembles a finding described by Bevins and Ayres (1991) and supports their conclusion that a ceiling effect did not prevent $\mathrm{T}$ from evoking more suppression than $\mathrm{L}$. This conclusion implies that $\mathrm{T}$ and $\mathrm{L}$ had similar conditioned values at the end of training. Thus, the greater freezing to $\mathrm{T}$ than to $\mathrm{L}$ at that time should not be ascribed to the greater conditioned value of $\mathrm{T}$.

Third, the barpress suppression measure found that overconditioning weakened the CR to $\mathrm{T}$ and $\mathrm{L}$ equally. This result is predicted by the Rescorla and Wagner (1972) model provided that $\mathrm{T}$ and $\mathrm{L}$ have similar asymptotic conditioned value and salience before the compound training phase. If that assumption is valid, then the greater freezing to $T$ than to $\mathrm{L}$ at the end of element conditioning is not due to a difference in the conditioned value or salience of these CSs.

Fourth, the freezing measure found that overconditioning weakened the $\mathrm{CR}$ to $\mathrm{T}$. Overconditioning could not be expected to weaken freezing much to L, because L controlled little freezing to be weakened. However, under the assumptions of the Rescorla and Wagner (1972) model, the fact that overconditioning weakened freezing to $\mathrm{T}$ implies that $\mathrm{L}$ must have had the strong conditioned value suggested by the strong barpress suppression to $\mathrm{L}$ during element training rather than the weak value suggested by the weak freezing to $\mathrm{L}$ during element training. If L's conditioned value was strong, then the weak freezing that $\mathrm{L}$ evoked cannot be blamed on its weak conditioned value. The implication is that the nature of the CS determines the form of the CR.

A potential weakness of our overconditioning design is that it did not contain a control group that received continued acquisition to $\mathrm{T}$ and $\mathrm{L}$ separately when the experimental group received conditioning to the TL compound. Such a control group might have shown a strong postasymptotic performance deficit such as that described earlier in this laboratory (see Figure 1 of Ayres, Moore, \& Vigorito, 1984). If so, then our interpretation of overconditioning in terms of the Rescorla and Wagner model would be invalid. It should be noted, however, that the deficit described earlier was obtained with extremely weak shock parameters $(0.4 \mathrm{~mA}, 0.5 \mathrm{~s})$ compared with those used here $(0.8 \mathrm{~mA}, 1 \mathrm{~s})$. It also involved more massed training (six L or T CSs per session vs. one of each used here). Moreover, the deficit developed rapidly over 11 days of training. Here, in contrast, we saw no sign of a deficit in 16 days of element-training before compound training.

\section{Experiment 4: A Double Dissociation}

The extant literature and the data presented so far have stressed what might be termed a single dissociation between freezing and barpress suppression to $\mathrm{T}$ and $\mathrm{L}$ : When suppression to $\mathrm{T}$ and $\mathrm{L}$ is equally strong, freezing is greater to $\mathrm{T}$. If, however, the nature of the $\mathrm{CS}$ determines the form of $\mathrm{CR}$, then it might be possible to reveal other types of dissociation. For example, a second type of dissociation might be one in which suppression is weaker to $\mathrm{T}$ than to $\mathrm{L}$ but freezing to $\mathrm{T}$ and $\mathrm{L}$ is similar. A third type of dissociation, called a double dissociation, would be one in which suppression is weaker to $\mathrm{T}$ than to $\mathrm{L}$ but freezing is stronger to $\mathrm{T}$. We might call these three dissociations Types 1, 2, and 3, respectively. The Type 3 (double) dissociation would be especially compelling evidence against the idea that the greater freezing to $\mathrm{T}$ reflects $\mathrm{T}$ 's greater conditioned value. Rather, that evidence would argue strongly that the nature of the CS determines the form of the CR. In Experiment 4 , we sought to demonstrate such a dissociation.

Our strategy was as follows. First, we conditioned L so that it evoked moderate-to-strong suppression. Then we reinforced one $\mathrm{T}$ and one $\mathrm{L}$ trial in each of four sessions. From experience, we knew that suppression to $\mathrm{T}$ would catch up with suppression to $\mathrm{L}$ in about four sessions. About midway through its conditioning, we knew that $\mathrm{T}$ would evoke moderate suppression but less than that evoked by L. The question was: Would $\mathrm{T}$ still evoke more freezing at that point?

\section{Method}

\section{Subjects}

The subjects were 20 male and 20 female Holtzman-derived albino rats bred in our colony. All had recently served in a study of conditioned suppression involving conditioning and extinction to $\mathrm{L}$ but not $\mathrm{T}$. In that study, the rats' free-feeding weights had been reduced by $20 \%$, and that reduction was maintained here. The reduced weights ranged from 232 to $346 \mathrm{~g}$ in the female rats and from 358 to $497 \mathrm{~g}$ in the male rats. The colony was lighted on a $16: 8 \mathrm{hr}$ light:dark cycle. Experimental sessions occurred during the light part of the cycle.

\section{Apparatus}

The apparatus was unchanged except that for 6 male and 6 female rats, the operant boxes were housed in a different room, and a highvoltage, high-resistance shock source provided the shock US. The shock was scrambled through a relay sequencing scrambler (Hoffman $\&$ Fleshler, 1962). Because that scrambler seems to produce a more effective shock than the Grason-Stadler shocker scramblers used in the previous experiments and with the remaining 28 rats here, we reduced the shock intensity from 0.8 to $0.5 \mathrm{~mA}$ for these 12 rats.

\section{Procedure}

The experiment was performed in three systematic replications (Sidman, 1960), each having two phases - a preliminary phase and a final phase. The preliminary phase was designed to ensure weak suppression to $\mathrm{T}$ and moderate-to-strong suppression to $\mathrm{L}$ at the start of the final phase. The final phase consisted of four 1-hr sessions, each with one $\mathrm{T}+$ and one $\mathrm{L}+$ trial. In each replication there were an equal number of male and female rats. For half of the rats, the order of trials across the 4 days was T L, L T, L T, and T L. For the remaining rats, the order was $\mathrm{L} T, \mathrm{~T} L, \mathrm{~T} \mathrm{~L}$, and $\mathrm{L} \mathrm{T}$. For all the rats, $\mathrm{L}$ terminated with a 1 -s shock, and $\mathrm{T}$ terminated with a 0.5 -s shock. A shorter shock duration was used for $\mathrm{T}$ in the hopes that suppression to $\mathrm{T}$ would not quite catch up to suppression to L, perhaps yielding a steady state preparation in which a double dissociation could be sought over an extended period. That hope was not realized. 
Each replication was unique in its preliminary training. Each change in that training was intended to produce a better approximation to the desired entering behaviors: weak suppression to $\mathrm{T}$ and moderate-to-strong suppression to L. In Replication $1(N=12)$, preliminary training consisted of one session with two L- trials. In Replication 2 $(N=12)$, it consisted of one session with two $\mathrm{L}+$ trials. In Replication $3(N=16)$, it consisted of two sessions. In Session 1, there were two $\mathrm{L}+$ trials; in Session 2, there was one $\mathrm{T}$ - and one $\mathrm{L}$ - trial.

Direct observations. Beginning on Day 1 of the final phase, a single trained observer (Ayres) did all the scoring in Replications 1 and 2. This was accomplished by training only four rats at a time. In Replication 2, a second observer, unaccustomed to live scoring of multiple animals, scored simultaneously on Days 2 and 3. The Pearson product-moment correlation coefficient between the two observers' $p$ (freezing) scores during CS trials was .84 on Day 2 and .93 on Day 3. In Replication 3, eight rats were trained at a time. One pair of trained observers scored the rats in Boxes 1-4, and a second pair scored the rats in Boxes 5-8. The correlation between pairs of $p$ (freezing) scores during the CS was .91. Because each rater in Replication 3 rated the same number of trials, the mean of each pair of ratings was taken as the best estimate of freezing.

\section{Results}

The pattern of results in the final phase was similar for each of the three replications. Suppression to T was initially weaker than suppression to L but caught up to the suppression to L by the end of training. Freezing was initially weaker to $\mathrm{T}$ than to $\mathrm{L}$ but surpassed the freezing to $\mathrm{L}$ midway through training. The results of the three replications combined are shown in Figure 11. The plots are based on the results of 39 of the 40 rats. One rat was excluded because after the first trial, it froze in the back of the box for roughly the last 55 min of every session. It thus provided no barpressing to be suppressed, and its freezing to $\mathrm{L}$ and $\mathrm{T}$ could not be distinguished from its freezing to contextual cues.

Averaged over Trials 2 and 3, the mean suppression ratios to $\mathrm{T}$ and $\mathrm{L}$ were .14 and .06 , respectively, and the mean $p$ (freezing) scores were .33 and .18. Both the differences between the suppression scores and between the freezing scores were significant, $t \mathrm{~s}(28)>3.65$. Thus, $\mathrm{T}$ evoked more freezing than $\mathrm{L}$ did even when $\mathrm{T}$ evoked less barpress suppression. This is evidence for a Type 3 (double) dissociation. This analysis, however, is potentially biased in that some individual rats may have suppressed more to $\mathrm{T}$ than to $\mathrm{L}$ or may have suppressed completely to $\mathrm{T}$. If individuals suppressed more to $\mathrm{T}$ than to $\mathrm{L}$, then greater freezing to $\mathrm{T}$ in those rats would not be newsworthy, and that freezing would have contributed to the freezing differences just described. In a similar vein, if individuals suppressed completely to $\mathrm{T}$, then, because of ceiling effects, their data might be suspect even if they also suppressed completely to L. Finally, if individual rats showed little evidence of conditioning to $\mathrm{T}$, as assessed by barpress suppression, then there would be no reason to expect them to freeze to $\mathrm{T}$. Their data should be excluded as well. Accordingly, we reanalyzed the data excluding rats whose mean suppression ratios averaged over Trials 2 and 3 were zero to T or were smaller than their suppression ratios to L; we also excluded any rats whose mean
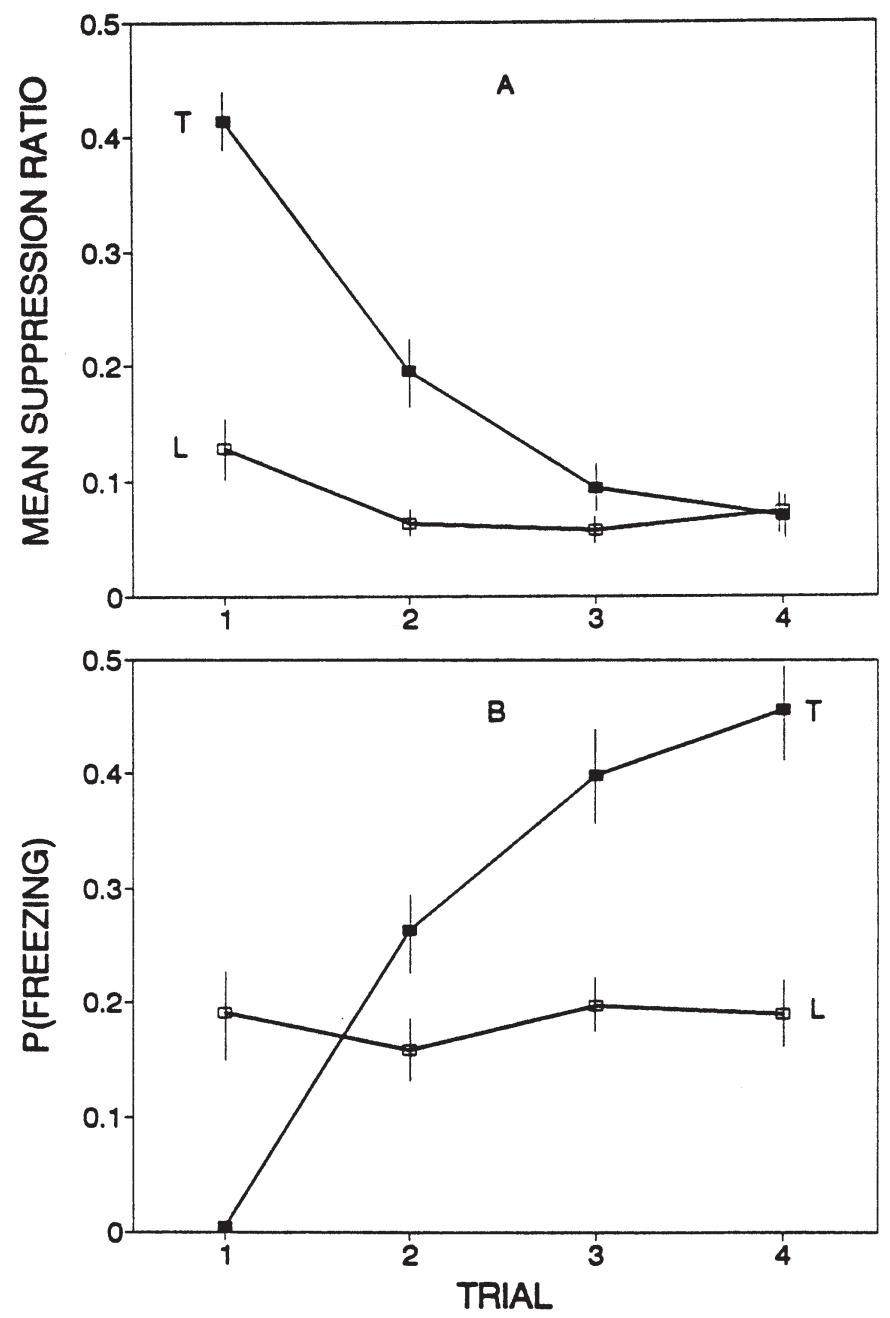

Figure 11. Barpress suppression (Panel A) and freezing (Panel B) during the final phase of Experiment 4. Vertical lines through data points show plus and minus one standard error of the mean.

suppression ratios to $\mathrm{T}$ on those trials exceeded .40 . The remaining sample included 22 rats whose mean suppression ratios to $\mathrm{T}$ and $\mathrm{L}$ were .16 and .04 , respectively, and whose mean $p$ (freezing) scores to T and L were .26 and .19. Both the differences between the suppression ratios and between the freezing scores were significant, $t \mathrm{~s}(21)>2.48$. The new analysis, then, also provided evidence for a Type 3 (double) dissociation.

\section{Pre-CS Responding}

Throughout the final phase of training, the pre-CS response rates were very similar for $\mathrm{T}$ and $\mathrm{L}$. More specifically, on Trials 2 and 3 combined, the mean rates before $\mathrm{T}$ and $\mathrm{L}$ were 13 and 14 responses per minute, respectively. On these same trials pre-CS freezing was rare, occurring on fewer than $2 \%$ of the samples. 


\section{Type 2 and 3 Dissociations in Experiments 1, 2, and 3}

Although Experiments 1, 2, and 3 were not designed to reveal Type 2 or 3 dissociations, the strategy of Experiment 4 can be applied retrospectively to those experiments. That strategy was to compare performance to T midway through its conditioning with performance to an already well-conditioned L. Applying that idea to Experiments 1, 2, and 3, we can retrospectively compare performance to $\mathrm{T}$ midway through its conditioning with performance to $\mathrm{L}$ during the later stages of its conditioning. Experiment 1 had four measures of element conditioning, and Experiment 2 had five (see Figures 1 and 4). We can thus compare performance to $\mathrm{T}$ on Measures 2 and 3 combined, with performance to L on Measure 4 in Experiment 1 and on Measures 4 and 5 combined in Experiment 2. Experiment 3 had eight measures of element conditioning. In that experiment, we can compare performance to $\mathrm{T}$ on Measures 2 and 3 combined with performance to L on Measures 4 through 8 combined. (As shown in Figure 8, Experiment 3 suggested that performance was asymptotic by Measure 4.) Each experiment thus provides an index of performance to $\mathrm{T}$ midway through conditioning and an index of performance to $\mathrm{L}$ late in conditioning. Experiments 1 and 2 both involved betweensubjects comparisons of performance to $\mathrm{T}$ and L, and Experiment 3, as in Experiment 4, provided a within-subjects comparison of performance to $\mathrm{T}$ and $\mathrm{L}$.

Looking first at the results of Experiments 1 and 2 combined, we find that the mean suppression ratio to $\mathrm{T}$ midway through its conditioning was .19. The mean suppression ratio to L late in its conditioning was .10. Suppression to T was significantly weaker than suppression to $\mathrm{L}, t(62)=2.65$. Correspondingly, the mean $p$ (freezing) scores to $\mathrm{T}$ and $\mathrm{L}$ were .15 and .09, respectively. Freezing was significantly stronger to T, $t(62)=1.79, p<.05$, one-tailed. Because Experiments 1 and 2 involved between-subjects comparisons of performance to $\mathrm{T}$ and $\mathrm{L}$, we could not exclude rats that suppressed more to $\mathrm{T}$ than to L, as we did in Experiment 4. However, we could exclude rats trained with $\mathrm{T}$ who suppressed completely to it or who had suppression ratios exceeding .40. When the data were reanalyzed with such rats excluded, the mean suppression ratios to $\mathrm{T}$ and $\mathrm{L}$ were .19 and .10 , respectively, and the corresponding mean $p$ (freezing) scores were .14 and .09. Suppression to $\mathrm{T}$ was significantly weaker than suppression to $\mathrm{L}$, $t(57)=2.79$, but the greater freezing to $\mathrm{T}$ was not statistically significant, even with a one-tailed test, $t(57)=1.62$. Thus, we found evidence in the combined data of Experiments 1 and 2 for a Type 2 dissociation-weaker suppression to $\mathrm{T}$ than to $\mathrm{L}$ but similar freezing to $\mathrm{T}$ and $\mathrm{L}$.

Experiment 3 involved a within-subjects comparison of performance to $\mathrm{T}$ and $\mathrm{L}$. We were therefore able to exclude rats that suppressed more to $\mathrm{T}$ midway through conditioning than they did to L late in conditioning, rats that suppressed completely to $\mathrm{T}$, and rats that had suppression ratios to $\mathrm{T}$ that exceeded .40. Such exclusions reduced the sample from 16 to 10 rats. For these 10 rats, the mean suppression ratio to $\mathrm{T}$ midway through conditioning was .21 and the mean to
L late in conditioning was .08. Suppression to T was significantly weaker than suppression to $\mathrm{L}, t(9)=4.03$. The corresponding mean $p$ (freezing) scores were .14 for $\mathrm{T}$ and .08 for L. There was more freezing to $\mathrm{T}$ than to $\mathrm{L}, t(9)=2.66$. Experiment 3 thus provides additional evidence for a Type 3 (double) dissociation.

\section{Discussion}

Experiment 4 yielded evidence for a Type 3 (double) dissociation: stronger freezing to $\mathrm{T}$ than to $\mathrm{L}$ even when barpress suppression was weaker to T. When the logic of Experiment 4 was applied retrospectively to the data of Experiments 1, 2, and 3, we found evidence in Experiments 1 and 2 combined for a Type 2 dissociation: similar freezing to $\mathrm{T}$ and $\mathrm{L}$ despite weaker barpress suppression to T. Experiment 3 revealed additional evidence for a Type 3 (double) dissociation.

When $\mathrm{T}$ evokes significantly weaker barpress suppression than L, it is difficult to argue that its ability to evoke freezing similar to that evoked by $\mathrm{L}$ is due to its similar conditioned value. The argument is even more strained if $\mathrm{T}$ evokes more freezing than L despite evoking weaker barpress suppression. Evidence for Type 2 dissociations and, especially, for Type 3 (double) dissociations thus offer strong support for the conclusion that the nature of the CS is a determinant of the form of the Pavlovian CR (strong vs. weak freezing).

\section{General Discussion}

In four experiments, we found evidence that the nature of the CS affects the form of the CR in Pavlovian fear conditioning. In Experiment 1, we found that light evoked less freezing than tone despite being at least as capable of blocking conditioning to a third CS. In Experiment 2, we found that tone and light evoked different levels of freezing despite having similar abilities to support second-order conditioning to a third CS. In Experiment 3, we found evidence that overconditioning (reinforcing the tone + light compound after training the elements separately to asymptote) weakened the conditioned values of tone and light. Reduced responding to tone is predicted by the Rescorla and Wagner model only under the assumption that tone's companion, light, is well conditioned at the start of compound training. If the light is indeed well conditioned, then its failure to evoke much freezing cannot be ascribed to lack of conditioned value. Experiment 4 yielded evidence for a double dissociation between the barpress suppression and freezing evoked by tone and light. This evidence suggested that under some conditions it is possible for tone to evoke less barpress suppression than light and still evoke more freezing. This finding argues strongly against the view that light evokes weaker freezing because it has less conditioned value than does tone. When we applied the logic of Experiment 4 retrospectively to the data of Experiments 1, 2, and 3, we obtained more evidence for similar dissociations. All of these findings support the view that the nature of the CS is a determinant of the form of the CR (strong vs. weak freezing). 
Our conclusion that light evokes less freezing than tone despite having similar conditioned value has interesting implications for the literature on "selective associations" (for a review, see Bevins, 1992). In that literature, the finding that Stimulus A evokes a stronger CR than Stimulus B is part of the evidence one uses to infer that Stimulus A is selectively associated with a US. In reality, however, such evidence only shows that the two stimuli evoke different levels of performance, just as tone and light evoke different levels of freezing. Before anything can be said about different strengths of association, evidence for differential ability to block or to serve as a second-order reinforcer or to foster overconditioning would seem useful. Could it be that a reexamination of selective "associations" using these tools would yield results similar to ours (i.e., differential performance despite similarity in association)?

Why does light evoke less freezing than does tone? Sigmundi and Bolles (1983) considered several possibilities, one of the more interesting being the idea that

[F]or rats, audition has evolved as a primary receptor for detecting predators at a distance so that many auditory CSs tend to control antidetection behavior such as freezing. On the other hand, the rat's visual system may have been phylogenetically ineffective as a distal sensor for predators. By the time a rat can see a predator, it might be too late to perform successful antidetection behaviors. If this were the case, then in the presence of visual danger signals, the rat should implement another defensive strategy such as moving to a safe place or preparing a counterattack. Such strategies would be difficult to recognize when testing the rat in a conditioning chamber that has no escape routes or places of safety, as in the present studies. (p. 211)

Although provocative, this speculation faces two problems.

First, the range of auditory and visual stimuli that have been compared is very narrow. White noise has been shown to produce more freezing than light (Sigmundi \& Holles, 1983; Sigmundi et al., 1980), and pulsing white noise has been shown to produce more freezing than flashing light (Ayres et al., 1985). Tone has been shown to produce more freezing than an increase in light (Bevins \& Ayres, 1991; van Willigen et al., 1987; and our studies) or a decrease in light (Bevins \& Ayres, 1991). This is the evidence for the generality of the auditory versus visual distinction. In contrast, the present Experiment 3 found similar freezing evoked by click and light, a result that at least potentially questions that generality. (Recall, though, that the click was produced by a relay mounted on the chamber. Undoubtedly, there was a vibratory component. That component may have fostered defensive behavior incompatible with freezing.)

Second, little progress has been made in identifying "another defensive strategy" that rats use in the presence of visual CSs (Albert, 1990; Fanselow \& Lester, 1988). One implication of this failure to find a defensive behavior unique to light is that when we conclude from our present evidence that the form of the CR evoked by feared CSs depends on the nature of the CS, we can point only to quantitative differences in form (differences in amount of freezing). We cannot describe any qualitative differences in the behaviors evoked by light and tone in fear conditioning analogous to those described by Holland (1977) in appetitive conditioning.

One puzzle that does appear to have been solved is how light and tone can evoke similar levels of barpress suppression despite evoking different levels of freezing. This dissociation appears paradoxical under the widely held assumption that freezing mediates barpress suppression. A solution to this paradox was provided by Bevins and Ayres (1992). They found that light and tone evoked similar withdrawal from the bar area. Because leaving the bar area is a sufficient condition for barpress suppression, it is possible for the two cues to evoke similar suppression despite evoking different levels of freezing.

\section{References}

Albert, M. L. (1990). Conditioning to a compound CS and the observation of CS-elicited behavior in 1-trial simultaneous and 1-trial backward conditioning procedures. Unpublished doctoral dissertation, University of Massachusetts, Amherst.

Annau, Z., \& Kamin, L. J. (1961). The conditioned emotional response as a function of intensity of the US. Journal of Comparative and Physiological Psychology, 54, 428-432.

Ayres, J. J. B., Axelrod, H., Mercker, E., Muchnik, F., \& Vigorito, M. (1985). Concurrent observations of barpress suppression and freezing: Effects of CS modality and on-line vs. off-line training upon posttrial behavior. Animal Learning \& Behavior, 13, 44-50.

Ayres, J. J. B., Moore, J. W., \& Vigorito, M. (1984). Hall and Pearce negative transfer: Assessments in conditioned suppression and nictitating membrane conditioning experiments. Animal Learning \& Behavior, 12, 428-438.

Bevins, R. A. (1992). Selective associations: A methodological critique. Psychological Record, 42, 57-73.

Bevins, R. A., \& Ayres, J. J. B. (1991). Two issues in Pavlovian fear conditioning: Selective fear of bright vs. dark, and CS determinants of CR form. Behavioural Processes, 24, 211-218.

Bevins, R. A., \& Ayres, J. J. B. (1992). Rats' location during conditioned suppression training. Animal Learning \& Behavior, 20, 8 16.

Davis, M. (1974). Sensitization of the rat startle response by noise. Journal of Comparative and Physiological Psychology, 87, 571578.

Fanselow, M. S., \& Lester, L. S. (1988). A functional behavioristic approach to aversively motivated behavior: Predatory imminence as a determinant of the topography of defensive behavior. In R. C. Bolles \& M. D. Beecher (Eds.), Evolution and learning (pp. 185-212). Hillsdale, NJ: Erlbaum.

Helmstetter, F. J., \& Fanselow, M. S. (1989). Differential secondorder aversive conditioning using contextual stimuli. Animal Learning \& Behavior, 17, 205-212.

Hendry, J. S. (1982). Summation of undetected excitation following extinction of the CER. Animal Learning \& Behavior, 10, 476482.

Hoffman, H. S., \& Fleshier, M. (1962). A relay sequencing device for scrambling grid shock. Journal of the Experimental Analysis of Behavior, 5, 329-330.

Holland, P. C. (1977). Conditioned stimulus as a determinant of the form of the Pavlovian conditioned response. Journal of Experi- 
mental Psychology: Animal Behavior Processes, 3, 77- 104.

Kamin, L. J. (1968). “Attention-like” processes in classical conditioning. In M. R. Jones (Ed.), Miami Symposium on the Prediction of Behavior: Aversive stimulation (pp. 9-31). Coral Gables, FL: University of Miami Press.

Lubow, R. E. (1989); Latent inhibition and conditioned attention theory. New York: Cambridge University Press.

Reberg, D. (1972). Compound tests for excitation in early acquisition and after prolonged extinction of conditioned suppression. Learning and Motivation, 3, 246-258.

Rescorla, R. A. (1970). Reduction in the effectiveness of reinforcement after prior excitatory conditioning. Learning and Motivation, 1, 372-381.

Rescorla, R. A., \& Wagner, A. R. (1972). A theory of Pavlovian conditioning: Variations in the effectiveness of reinforcement and nonreinforcement. In A. H. Black \& W. F. Prokasy (Eds.), Classical conditioning: II. Current research and theory (pp. 64-99). New York: Appleton-Century-Crofts.
Sidman, M. (1960). Tactics of scientific research. New York: Basic Books.

Sigmundi, R. A., \& Bolles, R. C. (1983). CS modality, context conditioning, and conditioned freezing. Animal Learning \& Behavior, 11, 205-212.

Sigmundi, R. A., Bouton, M. E., \& Bolles, R. C. (1980). Conditioned freezing in the rat as a function of shock intensity and CS modality. Bulletin of the Psychonomic Society, 15, 254-256.

van Willigen, F., Emmett, J., Cote, D., \& Ayres, J. J. B. (1987). CS modality effects in one-trial backward and forward excitatory conditioning as assessed by conditioned suppression of licking in rats. Animal Learning \& Behavior, 15, 201-211.

Submitted April 1995; revised July 1995; accepted August 3, 1995. 